\title{
1 Geomorphic regime modulates hydrologic control of chemical weathering in the
}

2 Andes-Amazon

Mark Torres $^{1^{*}}$, A. Joshua West ${ }^{1}$, and Kathryn E. Clark ${ }^{2,3}$

1 Department of Earth Sciences, University of Southern California, Los Angeles, USA 2 School of Geography and the Environment, University of Oxford, UK.

3 Department of Earth and Environmental Science, University of Pennsylvania, Philadelphia, USA (present address)

\section{${ }^{*}$ Corresponding Author}

marktorr@usc.edu (909) 8157857

3651 Trousdale Parkway

14 Los Angeles, Ca 90089

15 Zumberge Hall of Science Room 117

16

17

18

19

20

21

22 


\section{ABSTRACT}

The interplay between the hydrologic processes that supply, store, and route water in catchment systems and the chemical weathering reactions that add and remove solutes acts as an important control on chemical weathering fluxes. In this study, we use paired measurements of solute chemistry and runoff in four nested catchments that span the transition from the Andes Mountains to the Amazonian foreland floodplain in Peru in order to investigate the links between hydrology and weathering processes and to determine how these links change across a geomorphic gradient. All of the sites show variation in elemental concentrations and ratios with runoff consistent with hydrologically driven changes in lithologic sources, the extent of secondary mineral precipitation, and, potentially, fluid flow paths. In the Andean sites, solute concentrations are relatively constant despite large changes in runoff. This is in direct contrast to the foreland floodplain site, where solute concentrations are diluted as runoff increases. In the Andes-Amazon, the concentration-runoff behavior is correlated with the mean catchment slope angle, which suggests that erosional processes, by modulating the timescales over which weathering reactions occur within the critical zone, can be an underlying control on solute production and therefore on chemical weathering. Due to the covariation between the geomorphic and hydrologic controls on chemical weathering, weathering fluxes in Andean sites are more sensitive to seasonal changes in runoff than in the foreland floodplain site.

\section{Introduction}

The chemical transformation of minerals in Earth's critical zone (Brantley et al. 2014) plays an important role in many processes such as soil development (Graham et al. 2010), cycling of essential nutrient elements (Chadwick et al. 1999; Porder et al. 2007), and regulation of Earth's climate via the transfer of carbon between the surficial and rock reservoirs over geologic timescales (Walker et al. 1981; Berner et al. 1983; Beaulieu et al. 2012). It has long been recognized that the supply, storage, and routing of water influences the rate of dissolution of primary minerals and precipitation of secondary phases. The importance of hydrology is readily apparent from the observation that concentrations of dissolved ions derived from weathering are correlated with runoff and rarely show simple dilution with increasing flow in streams and rivers (Godsey et al. 2009, Moon et al. 2014). Consequently, chemical weathering fluxes are closely tied to changes in precipitation and/or river runoff (Dunne 1978; Bluth and Kump 1994; Anderson et al. 1997; Gaillardet et al. 1999; West et al. 2005; Gabet et al. 2006; Hartmann et al. 2009; Maher 2011; Eiriksdottir et al. 2013). Models suggest that the hydrologic control on weathering, which is central to the global climate-weathering feedback, may depend on erosional regime (West 2012; Maher and Chamberlain 2014), but this dependence remains to be fully understood.

The extent to which solute concentrations are correlated with runoff (i.e. the "concentration-runoff relationship") varies substantially between different elements (e.g., Kirchner and Neal 2013). In many catchments, the concentrations of base cations (i.e. $\mathrm{Ca}, \mathrm{Mg}, \mathrm{Na}$, and $\mathrm{K}$ ) and silicon are highly correlated with runoff and exhibit a "chemostatic" response to flow whereby the variation in solute concentrations is substantially smaller than the variation in runoff (Godsey et al. 2009; Clow and Mast 2010; Stallard and Murphy 2014). However, concentration-runoff relationships for base cations and silicon vary from one river to another, ranging from effectively chemostatic behavior to significant dilution with increasing runoff (Godsey et al. 2009, Moon et al. 2014).

While multiple mechanisms can generate the concentration-runoff relationships for weathering-derived solutes observed in natural systems (e.g., Johnson et al. 1969, 
104 Christophersen et al. 1990, Godsey et al. 2009, Maher 2011, Maher and Chamberlain 2014), all of the mechanisms share some basic principles. Fundamentally, runoff rates reflect the supply, storage, and routing of water in the catchment system (Beven 2012). These factors affect the amount of time it takes precipitation to transit through the catchment and become river flow (i.e. the fluid transit time) as well as the physical and chemical properties of the flow path that fluids take on their way to the channel (e.g., the water saturation, porosity, and primary mineral abundances). The fluid transit time and the flow path properties can affect chemical weathering reactions by modifying the time over which water-rock reaction can occur and the chemical and physical properties of the material undergoing reaction respectively. Consequently, concentration-runoff relationships should, to first order, reflect the hydrologic controls on chemical weathering fluxes in catchment systems (Godsey et al. 2009, Maher 2011, Maher and Chamberlain 2014).

Multiple mechanisms can generate runoff in a single catchment system depending on precipitation fluxes and antecedent conditions (Beven 2012). As a result, concentration-runoff relationships may show temporal variability within a single catchment. For example, runoff generation during large storms may dominantly result from flow through near-surface flow paths where fluids interact minimally with primary reactive minerals (e.g., Bonell and Gilmour 1978, Calmels et al. 2011, Stallard and Murphy 2014). In contrast, river water during base flow conditions may dominantly be sourced from deeper subsurface flow paths with longer transit times (Beven 2012, Tipper et al., 2006, Calmels et al. 2011). Systematic change in the dominant runoff generating mechanism at high runoff could considerably affect weathering fluxes because storm events, which transport the large volumes of water, may have shorter transit times and flow through zones with distinct mineralogy, influencing the extent of active weathering and solute acquisition. To identify the importance of such processes, measurements of concentration and runoff need to be made over the entire range of hydrologic conditions.

Ratios of solute concentrations of different elements are a particularly useful tool for investigating the underlying processes responsible for supplying solutes to rivers. The weathering of different lithologies produces distinct solute elemental ratios that can be used to determine the relative contributions from different lithologic sources (e.g., $\mathrm{Sr} / \mathrm{Na}$ and $\mathrm{Ca} / \mathrm{Na}$ ratios; Negrel et al. 1993, Gaillardet et al. 1999). Secondary processes, such as the removal of solutes via the precipitation of minerals or uptake by organisms, discriminate between elements and lead to characteristic variations in solute elemental ratios (e.g., element/Si ratios; Derry et al. 2005, Georg et al. 2007, Kurtz et al. 2011). Because weathering reactions produce depth-dependent variations in the chemistry and structure of the critical zone (e.g., Lebedeva et al. 2007), flow paths that sample different depths can produce fluids with unique solute elemental ratios (Boy et al. 2008, Kurtz et al. 2011). By investigating how elemental ratios vary with runoff (i.e. "ratio-runoff relationships"), hydrologically driven changes in biogeochemical processes and flow paths can be identified (Tipper et al. 2006, Boy et al. 2008, Calmels et al. 2011, Kurtz et al. 2011).

In this work, we consider how concentration-runoff and ratio-runoff relationships vary across a geomorphic gradient, and we explore what this variability implies about the links between chemical weathering, hydrology, and erosion. We focus on the transition from the steep slopes and rapid erosion in the Andes to the depositional setting of the Amazon foreland floodplain of Peru. Variation in geomorphic regime, such as across our study area, provides a natural gradient in the timescale over which minerals are exposed to chemical weathering reactions. In rapidly eroding environments, minerals undergo chemical reactions for relatively short periods of time before being exported from the 
155 catchment (i.e. short mineral residence time; West et al. 2005, Gabet and Mudd, 2009,

156 Ferrier and Kirchner 2008; Hilley et al. 2010, West 2012). In floodplain environments, sediment storage processes produce distributions of mineral residence times with relatively long means and heavy tails (Bradley and Tucker 2013). Variation in mineral residence times should lead to variation in the abundance of primary reactive minerals and, consequently, the rate at which solutes can be generated within the critical zone (West 2012, Maher and Chamberlain 2014).

While both geomorphic and hydrologic processes are thought to modulate chemical weathering fluxes, the question remains how these processes may interact in natural systems (Maher and Chamberlain 2014; Li et al. 2014). If fluid transit times and mineral residence times co-vary in natural systems, variations in chemical weathering fluxes may be amplified or dampened. The geodynamic processes that build relief typically also drive erosion (e.g., Montgomery and Brandon, 2002), and relief may control fluid transit times by creating longer fluid flow paths (McGuire et al. 2005), though evidence for this relationship remains equivocal (Tetzlaff et al. 2009). If fluid transit times and topographic length scales are positively correlated, then mountainous regions may be efficient chemical weathering systems because they have relatively long fluid transit times, short mineral residence times, and large water fluxes driven by orographic precipitation (Gaillardet et al. 2011, Li et al. 2014, Maher and Chamberlain 2014). These interactions may also control the processes fractionating stable isotopes of dissolved elements (Bouchez et al. 2013), such that understanding solute chemistry may unlock clues for interpreting the geologic record of variations in seawater isotopic composition (e.g., the Li isotope record; Misra and Froelich 2012).

This study takes advantage of samples taken at high temporal resolution (monthly to sub-daily sampling) across a relatively small area $\left(27830 \mathrm{~km}^{2}\right.$ or $0.6 \%$ of the entire Amazon basin) in the Andes and Amazon. The study design makes it possible to limit heterogeneity in lithology (which is known to exert a strong control on weathering processes; e.g., Bluth and Kump 1994; Gaillardet et al. 1999) while still considering very significant contrasts in erosional setting. We report time-series data of dissolved ion concentrations and use these data to determine how concentration-runoff relationships and ratio-runoff relationships of weathering-derived solutes vary between catchments. These relationships are used to infer how the hydrologic control on chemical weathering responds to variation in the geomorphic regime.

\section{METHODS}

\subsection{Study Site}

The sample set used in this study comes from the Kosñipata Valley and Madre de Dios floodplain in Peru (Fig. 1). Four nested catchments spanning over 4000 meters in elevation and $120 \mathrm{~km}$ in horizontal distance were sampled over the course of one year in order to capture the transition from Andes Mountains (> $400 \mathrm{~m}$ elevation; cf. Moquet et al. 2011) to the foreland floodplain (120 to 400 m elevation; Moquet et al. 2011). A consequence of the nested catchment design is that both mean catchment elevation and total catchment surface area are negatively correlated. The catchment properties presented below and in Table 1 (i.e. mean elevation, elevation range, and mean catchment slope angle) were all calculated using a digital elevation model derived from Shuttle Radar Tomography Mission data (90 x 90 m resolution; Jarvis et al. 2008). The mean catchment slope angles for the Andean sites (Way and SP; see below) calculated in this study are $1^{\circ}$ lower than those calculated in Clark et al. (2014) for the same catchments, which is likely due to different post-processing of the SRTM data. Because Clark et al. (2014) did not calculate mean catchment slope angles for the lower elevation 
sites (MLC and CICRA; see below) we only use the mean catchment slope angles calculated in this study to be consistent when comparing between sites.

\subsubsection{Andean Sites}

To constrain weathering processes occurring in the Andes, the Kosñipata River was sampled at the Wayqecha gauging station (Way) and at the San Pedro gauging station (SP; Fig. 1). The catchment upstream of the Wayqecha gauging station (S13 $09.732 \mathrm{~W} 7135.333$ ) has a total area of $50 \mathrm{~km}^{2}$, an elevation range of $2250-3910 \mathrm{~m}$, a mean elevation of $3204 \mathrm{~m}$, and a mean catchment slope angle of $25^{\circ}$ (Fig. 1; Clark et al. 2013). The catchment upstream of the San Pedro gauging station (S13 03.444 W71 32.664 ) has a total area of $161 \mathrm{~km}^{2}$, an elevation range of $1360-4000 \mathrm{~m}$, a mean elevation of $2778 \mathrm{~m}$, and mean catchment slope angle of $27^{\circ}$ (Fig. 1; Clark et al. 2013).

The dominant lithology in both the Way and SP catchments is a Paleozoic ( 450 Ma) metasedimentary mudstone unit with some carbonate cements (Carlotto Caillaux et al. 1996). A minor proportion (i.e. $21 \%$ by area) of the catchment defined at San Pedro gauging station is underlain by Paleozoic felsic plutonic rocks (Carlotto Caillaux et al. 1996; Clark et al. 2013). Soils in Andean landscapes have been previously classified as Inceptisols (Asner et al. 2014).

The mean annual air temperature in the Andean catchments ranges from $\sim 12$ to $19^{\circ} \mathrm{C}$, varying with the elevation (Girardin et al. 2014, Huaraca Huasco et al. 2014), with an adiabatic air temperature lapse rate of $4.94{ }^{\circ} \mathrm{C} \mathrm{km}^{-1}$ (Girardin et al. 2014). Catchmentwide mean annual rainfall values of $2299 \pm 115 \mathrm{~mm} \mathrm{yr}^{-1}$ (Way) and $2881 \pm 124 \mathrm{~mm} \mathrm{yr}^{-1}$ (SP) were determined for the period from 1998 to 2012 using calibrated TRMM data (Clark et al. 2014). During the study period (2010-2011), annual rainfall was $2519 \pm 335$ $\mathrm{mm} \mathrm{yr} \mathrm{r}^{-1}$ and $3112 \pm 414 \mathrm{~mm} \mathrm{yr}^{-1}$ for the Way and SP catchments respectively, slightly above the long-term average (Clark et al. 2014). Like air temperature, rainfall also shows a strong elevational dependence (Lambs et al. 2012, Clark et al. 2014). For the same $2010-2011$ period, annual runoff was estimated to be $3065 \mathrm{~mm} \mathrm{yr}^{-1}$ and $2796 \pm 126$ $\mathrm{mm} \mathrm{yr}^{-1}$ for the Way and SP catchments respectively. The discrepancy between rainfall and runoff at the Way catchment reflects, in part, the contribution of cloud water inputs to the total water budget and the fact that the annual discharge at this site is highly uncertain as it was calculated using 59 discrete measurements as opposed to the nearcontinuous discharge logging that was conducted at San Pedro (i.e. 4 measurements per hour). For both of the Andean catchments, a seasonal hysteresis between rainfall amounts and runoff is evident with runoff during the dry season (May - September) being sustained by relatively lower amounts of rainfall. Likely, this hysteresis reflects seasonal storage of rainfall as groundwater within fractured bedrock (Clark et al. 2014).

\subsubsection{Mountain Front Site}

To constrain weathering processes occurring over the entire range of elevations within the Peruvian Andes that contribute to the Amazonian weathering budget, the Alto Madre de Dios River was sampled at the Manu Learning Center (MLC). The MLC catchment (S12 47.334 W71 23.429) has a total area of $6025 \mathrm{~km}^{2}$, an elevation range of 452-5496 m, a mean elevation of $2012 \mathrm{~m}$, and mean catchment slope angle of $22^{\circ}$ (Fig. 1). The catchment area upstream of MLC is largely underlain by Paleozoic metasedimentary rocks, Paleozoic plutonic rocks, and Paleozoic marine sedimentary rocks (Mendívil Echevarría and Dávila Manrique, 1994; Carlotto Caillaux et al., 1996; Vargas Vilchez and Hipolito Romero, 1998; INGEMMET, 2013).

\subsubsection{Foreland Floodplain Site}


To constrain weathering processes in the foreland floodplain region, the Madre de Dios River was sampled at the CICRA research station (Fig. 1). The CICRA catchment ( $\mathrm{S} 1234.362 \mathrm{~W} 70$ 06.049) has a total area of $27830 \mathrm{~km}^{2}$, a mean elevation of $822 \mathrm{~m}$, elevation range of 219-5496 m, and a mean catchment slope angle of $9^{\circ}$ (Fig. 1). Because the CICRA catchment incorporates both the Andes and foreland-floodplain region, temperature is heterogeneous throughout the catchment. Near the sampling locality, meteorological stations (data available from http://atrium.andesamazon.org) record temperatures that typically range from $21-26^{\circ} \mathrm{C}$ with a mean of $\sim 24^{\circ} \mathrm{C}$ and precipitation volumes that range from 2600 to $3500 \mathrm{~mm} / \mathrm{yr}$, with mean values between 2700 and $3000 \mathrm{~mm} / \mathrm{yr}$ (Lambs et al. 2012). A majority of the annual rainfall in Peru occurs during the austral summer (Lambs et al. 2012, Clark et al. 2014). The catchment area of CICRA is largely underlain by sediments shed from the Andes with additional contributions from Cretaceous marine sediments and Cenozoic continental deposits (Räsänen et al., 1992, Mendívil Echevarría and Dávila Manrique, 1994; Carlotto Caillaux et al., 1996; Vargas Vilchez and Hipolito Romero, 1998; INGEMMET, 2013).

\subsection{Sampling Methodology}

Samples were collected between 2010 and 2011 from each catchment at approximately bi-weekly resolution as well as every three hours for a period of about two weeks starting on January $30^{\text {th }}$ in 2010 . However, only data collected with paired discharge measurement are reported here for the main sampling localities from the 2010-2011 sampling campaign. A total of $86,60,52$, and 23 paired discharge and dissolved element samples were collected from Way, SP, MLC, and CICRA respectively. Because the Wayqecha gauging station is immediately downstream of a confluence of two tributaries, the east (Alipachanca) and west (Huallpayuncha) tributaries were also sampled periodically for chemical analysis. Both tributaries were sampled at the same time as the main stem downstream of the confluence (i.e. at the Wayqecha gauging station) in order to investigate mixing relationships. Following Clark et al. (2014), samples collected between December and March are labeled wet season samples, samples collected in April are labeled wet-to-dry season transition samples, samples collected between May and September are labeled dry seasons samples, and samples collected between October and November are labeled dry-to-wet season transition samples.

Samples for major and minor element analysis were collected from the river surface in a clean polypropylene (PP) bottle, filtered onsite with a $0.2 \mu \mathrm{m}$ nylon filter and split into two aliquots stored in separate $60 \mathrm{~mL}$ high-density polyethylene bottles (HDPE). One aliquot was preserved with 2 drops of high purity $\mathrm{HCl}$ dispensed from an acid-washed Teflon dropper bottle for cation analyses. The other aliquot was left unpreserved for anion analysis. In the laboratory, samples with any remaining particulates (e.g., from flocculated aggregates forming after field filtration) were refiltered before analysis with a $0.2 \mu \mathrm{m}$ nylon filter.

Discharge was measured at each of the main sampling localities as described by Ballew (2011) and Clark et al. (2014). Briefly, river level was monitored manually at all sites and converted to discharge using a rating curve. A total of 28, 22, 20, and 11 points were used for the rating curve at the Way, SP, MLC, and CICRA catchments respectively. For the San Pedro site, river level was also monitored with a water level logger that recorded river level measurements every 15 minutes.

\subsection{Analytical Methodology}

Major and minor cation ( $\mathrm{Ca}, \mathrm{Mg}, \mathrm{Na}, \mathrm{K}, \mathrm{Si}$, Li, and $\mathrm{Sr}$ ) concentrations were measured on the acidified aliquot using an Agilent Microwave Plasma-Optical Emission 
Spectrometer (MP-OES). Precision and accuracy was assessed by analyzing a reference material after every 15 samples. For $\mathrm{Ca}, \mathrm{Mg}, \mathrm{Na}, \mathrm{K}, \mathrm{Si}$, the reference material ION-915 (Environment Canada) was used. For Li, the reference material TMDA-51.4 (Environment Canada) was used. For $\mathrm{Sr}$, an in-house prepared $\mathrm{SrCO}_{3}$ solution was used. Replicate analyses of each solution reveal analytical precision within $5 \%(1 \sigma)$ for each analyte.

Major anion $\left(\mathrm{SO}_{4}{ }^{2-}\right.$ and $\left.\mathrm{Cl}^{-}\right)$concentrations were measured on the un-acidified

\subsection{Data Processing}

\subsubsection{Correction for cyclic salt inputs}

Atmospheric deposition has been shown to be an important source of major elements in the Amazon system (e.g., Stallard and Edmond 1981, Moquet et al. 2011). To correct for this contribution, precipitation element/Cl' ratios are typically used. For this study, samples of local precipitation were collected and analyzed, and the new precipitation chemistry data was supplemented with previously published precipitation analyses (Stallard and Edmond 1981, Moquet et al. 2011). Because both elemental concentrations and ratios in precipitation show large variations (Fig. 2, and Tables A1-4), precipitation volume-weighted means are typically used to define the chemical composition of precipitation (e.g., Calmels et al. 2011). Because paired measurements of precipitation chemistry and volume for the studied catchments are not currently available, an alternative approach was utilized here. This method, which is detailed in the Supplementary materials, relies on the assumptions that 1 ) stream water reflects a two component mixture of solutes derived from weathering and precipitation and 2) seawater aerosols represent the dominant source of $\mathrm{Na}_{\text {and }} \mathrm{Cl}^{-}$ions to precipitation in the system (Stallard and Edmond 1981, Andreae et al. 1990).

\subsubsection{Calculation of concentration-runoff relationships}

Following Godsey et al. (2009), concentration-runoff relationships were modeled with a power law function where:

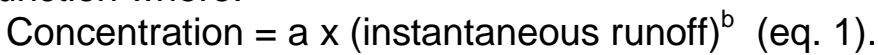

Non-linear regression of the data using eq. 1 and calculation of the uncertainties (i.e. $95 \% \mathrm{Cl}$ ) associated with the fitted parameters ( $a$ and $b$ ) was performed using the trustregion algorithm available in the MATLAB 2013a curve fitting toolbox. An arbitrary degrees of freedom-adjusted $R^{2}$ value of 0.3 was set in order to identify solutes that were correlated with runoff. For all of the catchments, analysis of the residuals of the power law fit revealed that a single concentration-runoff relationship misestimated the concentrations of specific subset of the data. So, in addition to fitting the data with eq. 1 using all the data points, fits were also calculated with subsets of the data that were selected based on criteria described in the results section. In all tables, the coefficients labeled "total fit" were calculated using all of the data points, the coefficients labeled "dominant fit" were calculated using a subset of the data pointed selected to reflect the dominant trend, and, for some sites, the coefficients labeled "subordinate fit" were calculated with a subset of the data points that showed a subordinate concentrationrunoff relationship. The specific data points used for each of the fits are indicated in supplementary Tables A1-4. Each catchment ultimately required different criteria to 
separate data points described by different concentration-runoff relationships (see section 3.2 below). The calculated values of the power law exponent and their $95 \%$ confidence intervals are presented in Table 2. The calculated values of all of the coefficients (i.e $a$ and $b$ in eq. 1) along with the degrees of freedom-adjusted $R^{2}$ values are presented in Tables A7-8. Both uncorrected and atmospheric-input corrected data were fit with eq. 1 in order to calculate concentration-runoff relationships for the concentrations of elements sourced solely from weathering reactions (i.e. the atmospheric-input corrected data) and compare them to concentration-runoff relationships for total solute concentrations (i.e. the uncorrected data).

\subsubsection{Calculation of ratio-runoff relationships}

For each of the studied catchments, variation in both the atmospheric input corrected and uncorrected $\mathrm{Sr} / \mathrm{Na}$ ratios with runoff were fit with a linear model using MATLAB 2013a. The uncertainties (i.e. $95 \% \mathrm{Cl}$ ) of the calculated slopes were used to assess whether or not the elemental ratios varied significantly with runoff (i.e. non-zero slopes). A linear regression was also used to test for correlation between $\mathrm{Na} / \mathrm{Si}$ and $\mathrm{Li} / \mathrm{Na}$ ratios at each of the sites. For other calculated elemental ratios (i.e. $\mathrm{Ca} / \mathrm{Na}, \mathrm{Na} / \mathrm{Si}$, and $\mathrm{Li} / \mathrm{Si}$ ), correlations with runoff were not modeled with any regression equations.

\section{RESULTS}

\subsection{Atmospheric inputs}

If the dissolution of $\mathrm{Cl}$-bearing evaporite minerals was a major contributor to the riverine solute budget for any of the sampled catchments, the application of the measured $\mathrm{Cl}^{-}$concentrations to correct for atmospheric contributions would be compromised. The overall low concentrations of $\mathrm{Cl}^{-}(2-15 \mu \mathrm{M}, 1-12 \mu \mathrm{M}, 6-31 \mu \mathrm{M}$, and 6$60 \mu \mathrm{M}$ for Way, SP, MLC and CICRA respectively; Tables A1-4) measured in the river samples and their similarity to the rainwater $\mathrm{Cl}^{-}$concentrations determined in this study (0.4-11.5 $\mu \mathrm{M}$ for samples with $\mathrm{Na} / \mathrm{Cl}^{-}$ratios near the seawater ratio; Tables A1-5) suggests negligible contribution of $\mathrm{Cl}^{-}$from evaporite dissolution, especially considering that our rainwater samples are dominantly from high elevations (> $450 \mathrm{~m}$ ) and Amazonian rainwater $\mathrm{Cl}^{-}$concentrations are known to increase with increasing proximity to the Atlantic ocean (Stallard and Edmond, 1981). Additionally, the relationship between element $/ \mathrm{Cl}^{-}$and $\mathrm{Na} / \mathrm{Cl}^{-}$ratios can be used to diagnose potential evaporite inputs. Marine evaporite deposits should have $\mathrm{Na} / \mathrm{Cl}^{-}$ratios near 1 , and thus would plot near the precipitation end-member $\left(\mathrm{Na} / \mathrm{Cl}^{-}=0.86\right)$ and influence the calculated element $/ \mathrm{Cl}^{-}$ratio based on the linear regression model. Based on the data from Stallard (1980) and Gaillardet et al. (1997), the $\mathrm{Ca} / \mathrm{Cl}^{-}$and $\mathrm{Mg} / \mathrm{Cl}^{-}$ratios of plausible evaporite end-members for the Amazon system can be estimated to range from 0.06-0.26 and 0.008-0.03 respectively, for $\mathrm{Na} / \mathrm{Cl}^{-}$ratios of $0.86-1$. Because these ratios are offset from the calculated best-fit line from our data, and no data appear to trend towards these values, significant evaporite contribution can be discounted and $\mathrm{Cl}^{-}$concentration can be reliably used to correct for atmospheric inputs (Fig. 2). However, if $\mathrm{Cl}^{-}$bearing evaporites do contribute significantly to the dissolved budget of $\mathrm{Cl}^{-}$in any of the studied catchments, our correction procedure would have the dual effect of removing both atmospheric and evaporite contributions to the dissolved load.

The calculated element/Cl' ratios for atmospheric inputs of $\mathrm{K}, \mathrm{Ca}, \mathrm{Mg}$, and $\mathrm{SO}_{4}{ }^{2-}$ (Tables A5-6) as well as the assumed $\mathrm{Na} / \mathrm{Cl}^{-}$ratio are all within the range of the ratios measured in precipitation samples collected as part of this study as well as those available from the literature (Stallard and Edmond 1981, Moquet et al. 2011; Fig. 2). Between the different catchments, there is no significant variation in the composition of major element/Cl ratios of atmospheric inputs. The average of the calculated $\mathrm{K} \mathrm{Cl}^{-}(0.4 \pm$ 
1), $\mathrm{SO}_{4}{ }^{2-} / \mathrm{Cl}^{-}(1.5 \pm 5.5), \mathrm{Ca} / \mathrm{Cl}^{-}(1.4 \pm 4.4)$, and $\mathrm{Mg} \mathrm{Cl}^{-}(0.8 \pm 3)$ ratios are all higher than the seawater values but, because of the large uncertainties associated with the fitting procedure, overlap within uncertainty (Table A6, Fig. 2). Elevated ratios for these elements in precipitation may be expected if there is a small contribution from dissolution of dust particles or, in the case of $\mathrm{K}$ and $\mathrm{SO}_{4}{ }^{2-}$, biogenic aerosols. The calculated $\mathrm{Sr} / \mathrm{Cl}^{-}$ ratios are comparable to the ratio presented in Gaillardet et al. (1997), which was calculated using the data of Furch (1984). The calculated $\mathrm{Li}^{\mathrm{Cl}} \mathrm{Cl}^{-}$ratios range from 0.0002 -0.008 and are $1-2$ orders of magnitude greater than the seawater $\mathrm{Li} / \mathrm{Cl}$ ratio $\left(4.8^{*} 10^{-5}\right)$. The average of the calculated $\mathrm{Si} / \mathrm{Cl}^{-}$ratios of the atmospheric-input end member for all of the sites is $1.7 \pm 5.8$. This apparent enrichment in $\mathrm{Si}$ in rainfall may be related to the dissolution of silicate mineral-rich dust (e.g., Reid et al. 2003) or the addition of solutes during the passage of rainfall through the forest canopy as throughfall (i.e. the addition of $\mathrm{Si}$ in preference to $\mathrm{Cl}^{-}$; Tobón et al. 2004).

Broadly, the fractional contribution of atmospheric deposition to the dissolved load at each of the study sites increases with decreasing mean catchment elevation due to an increase in $\mathrm{Cl}^{-}$concentrations. For each sample, the mean fractional contribution of atmospheric deposition to the dissolved load is tabulated in Tables A1-5.

\subsection{Intra-site variation in elemental concentrations with runoff}

The observed concentration-runoff relationships show three different types of variation: 1) variation between different elements within the same catchment, 2) temporal variation of a single element within a single catchment, and 3) variation between different catchments (Figs. 3-6, Tables 2, A7-8). The observed concentrationrunoff relationships are first discussed on a catchment-by-catchment basis before comparing the results between catchments in the discussion section.

In the Wayqecha catchment, all of the elements except for $\mathrm{Cl}^{-}$and $\mathrm{K}$ show systematic variation in concentration with runoff (i.e. adjusted $R^{2}>0.3$; Table 2) and the calculated values of the power law exponents are not significantly different between the atmospheric-input corrected and uncorrected samples (Table 2). Silicon has the lowest adjusted $R^{2}$ value (0.35; Fig. 3b; Table 2, A7-8), but this is consistent with the fact that it has a near-zero power law exponent $(-0.12 \pm 0.03$; Fig. $3 b$; Table 2,A7-8) and is thus expected to vary little with runoff. Relative to $\mathrm{Ca}, \mathrm{Mg}$ and $\mathrm{Sr}$, higher adjusted $\mathrm{R}^{2}$ values are observed for $\mathrm{Na}, \mathrm{Li}$, and $\mathrm{SO}_{4}{ }^{2-}$ despite the fact that all of these elements have relatively similar power law exponents (-0.29 to -0.41 ; Fig. 3a,c-d; Table 2,A7-8). Interestingly, the residuals of the power law concentration-runoff fits for $\mathrm{Ca}, \mathrm{Mg}$, and $\mathrm{Sr}$ are positively correlated with the sample $\mathrm{Sr} / \mathrm{Na}$ ratio while the residuals for the $\mathrm{Na}, \mathrm{Si}, \mathrm{Li}$, and $\mathrm{SO}_{4}{ }^{2-}$ concentration-runoff relationships are not. If the data are separated based on their $\mathrm{Sr} / \mathrm{Na}$ ratio, then samples with low $\mathrm{Sr} / \mathrm{Na}$ ratios (i.e. $>6.2 \mathrm{mmol} / \mathrm{mol}$; dominant samples/fit) have lower power law exponents for $\mathrm{Ca}, \mathrm{Mg}$, and $\mathrm{Sr}$ relative to the total fit (Fig. 3d, 7b; Table 2, A7-8).

In the San Pedro catchment, all of the elements except for $\mathrm{Cl}^{-}$and $\mathrm{K}$ show systematic variation in concentration with runoff (i.e. adjusted $R^{2}>0.3$ ) and the calculated values of the power law exponents are not significantly different between the atmospheric-input corrected and uncorrected samples (Table 2, A7-8). However, the power law fit to the total dataset systematically overestimates element concentrations at the highest runoff rates (Fig. 4a-d). To account for this, all the data at high temporal resolution during the wet season (see section 2.2) were fit with a separate power law relationship (i.e. subordinate fit, Figs. 4a-d; Table 2, A7-8). At low runoff $(<12 \mathrm{~mm} /$ day; i.e. dominant fit), all elements other than $\mathrm{Cl}^{-}$and $\mathrm{K}$ have concentration-runoff relationships characterized by negative and near zero power law exponents (Figs. 4a-d; Table 2, A7-8). Between the different elements, Si has the highest exponent value $(-0.10$ 
\pm 0.05 ; Fig. 4b). The elements $\mathrm{SO}_{4}{ }^{2-}, \mathrm{Li}$, and $\mathrm{Sr}$ have similar power law exponent values near -0.3 while the elements $\mathrm{Na}, \mathrm{Ca}$, and $\mathrm{Mg}$ have higher exponent values near -0.2 (Figs. 4a,c-d). At high runoff (>12 mm/day; i.e. subordinate fit), $\mathrm{Si}, \mathrm{Ca}, \mathrm{Mg}, \mathrm{Na}, \mathrm{SO}_{4}{ }^{2-}$ and $\mathrm{Sr}$ all have power law exponent values near -1 whereas the exponent for $\mathrm{Li}$ is distinctly lower (-1.6 \pm 0.5 ; Figs. 4a-d; Table 2, A7-8) and the exponent for $\mathrm{K}$ is distinctly higher $(1.65 \pm 0.5$; Table 2, A7-8). Additionally, the transition between the dominant and subordinate concentration-runoff relationships is marked by increases in the concentrations of $\mathrm{SO}_{4}{ }^{2-}, \mathrm{K}$, and $\mathrm{Li}$ (Fig. 4c; Table A2).

In the MLC catchment, all of the elements except for $\mathrm{Cl}^{-}$and $\mathrm{K}$ show systematic variation in concentration with runoff (i.e. adjusted $R^{2}>0.3$; Table 2, A7-8) and the calculated values of the power law exponents are not significantly different between the atmospheric-input corrected and uncorrected samples (Table 2, A7-8). For Li, the total power law fit overestimates concentrations for samples collected during storms in the dry season (June-August) and dry-to-wet season transition (October-November; Fig. 5c). When investigated in more detail, these dry season and dry-to-wet season transition samples are also relatively depleted in $\mathrm{Na}, \mathrm{Ca}, \mathrm{Mg}, \mathrm{Sr}$, and $\mathrm{Si}$, though to a lesser extent than observed for Li (Fig. 5a-d). To account for this, separate power law fits were calculated for samples collected between December and May (the wet season and wetto-dry season transition; i.e. dominant fit) and samples collected between June and November (the dry season and dry-to-wet season transition; i.e. subordinate fit; Fig. 5). It is worth noting that 2 of the 19 samples collected between June and November have concentration-runoff relationships consistent with the wet season samples and were therefore not included in the subordinate regression (Tables A3, A7-8).

For the MLC subordinate regression, all elements except for $\mathrm{Cl}^{-}$and $\mathrm{K}$ have power law exponent values near -1 (Figs. 5a-d; Tables 2, A7-8). For the MLC dominant fit, the calculated power-law exponents are higher than during the dry season (Figs. 5a$\mathrm{d}$; Tables 2, A7-8). For $\mathrm{Si}$, the power law exponent is the highest $(-0.25 \pm 0.04)$ of all of the elements (Fig. 5b, Tables 2, A7-8). Relative to $\mathrm{Si}$, the exponents are slightly lower for $\mathrm{Na}$, Li, and $\mathrm{Sr}(-0.36 \pm 0.08,-0.35 \pm 0.07$, and $-0.46 \pm 0.1$ respectively; Fig. $5 \mathrm{a}-\mathrm{d})$. The lowest exponent values are seen for $\mathrm{Ca}, \mathrm{Mg}$, and $\mathrm{SO}_{4}{ }^{2-}(-0.46 \pm 0.07,-0.47 \pm 0.06$, and $0.58 \pm 0.09$ respectively; Tables 2, A7-8).

In the CICRA catchment, all of the elements except for $\mathrm{Cl}^{-}$show systematic variation in concentration with runoff (i.e. adjusted $R^{2}>0.3$; Fig. 6; Tables 2, A7-8). For $\mathrm{Na}, \mathrm{Mg}$, and $\mathrm{Si}$, the power law exponents calculated from the atmospheric-input corrected data are significantly lower than the exponents calculated from the uncorrected data (Tables 2, A7-8). For all other elements, the calculated power law exponents are not significantly different between the corrected and uncorrected data (Tables 2, A7-8). The 3-hour resolution time-series sampling at CICRA reveals samples collected during the falling limb of wet season storms are relatively enriched in $\mathrm{Ca}, \mathrm{Sr}$, and Mg (Fig. 6d, Table A4). These samples showing elevated concentrations were excluded from the dominant regression. For both the dominant fit of the corrected and uncorrected data, $\mathrm{K}$ has the highest power law exponent $(-0.45 \pm 0.18$ and $-0.20 \pm 0.08$ respectively). Next to K, Si has the highest power law exponent for both the corrected and uncorrected data $(-0.65 \pm 0.21$ and $-0.4 \pm 0.11$ respectively). All of the other elements show power law exponents that are near -1 for the corrected data, with slightly higher values for the uncorrected data (Tables 2, A7-8).

\subsection{Variation in elemental ratios with runoff}

Due to variations in the concentration-runoff relationships for different elements within the same catchment, elemental ratios also vary with runoff. At the Wayqecha, San Pedro, and CICRA sites, $\mathrm{Na} / \mathrm{Si}$ ratios show a broad decrease with increasing runoff 
(Figs. 7c-10c). At the San Pedro site, the samples collected at the highest runoff rates

511

512

513 show a slight increase in $\mathrm{Na} / \mathrm{Si}$, but the ratio remains significantly lower relative to samples collected at the lowest runoff rates (Fig. 8c). At the MLC site, the variation in $\mathrm{Na} / \mathrm{Si}$ is complicated in that some samples collected at high runoff rates have similar $\mathrm{Na} / \mathrm{Si}$ ratios to those collected at low runoff rates (Fig. 9c). Similar to $\mathrm{Na} / \mathrm{Si}$ ratios, $\mathrm{Li} / \mathrm{Si}$ ratios also show a broad decrease with increasing runoff at all of the sites (Figs. 7c-10c). At the San Pedro site, Li/Si ratios are distinct from other sites in that there are maximum values at both high and low runoff (Fig. 8d). At the MLC catchment, Li/Si ratios are distinct in that there are minima at both high and low runoff (Fig. 9d).

In addition to $\mathrm{Na} / \mathrm{Si}$ and $\mathrm{Li} / \mathrm{Si}$ ratios, $\mathrm{Sr} / \mathrm{Na}$ ratios also show systematic variation with runoff in all of the catchments except Wayqecha (Figs. 7b-10b). For the Wayqecha catchment, $\mathrm{Sr} / \mathrm{Na}$ ratios of the low $\mathrm{Sr} / \mathrm{Na}$ samples do not vary systematically with discharge as evidenced by slopes that overlap with zero within the $95 \% \mathrm{Cl}$ for both the atmospheric-input corrected $\left(3.6^{*} 10^{-6} \pm 16^{*} 10^{-6}\right)$ and uncorrected $\left(4.2^{*} 10^{-6} \pm 15^{*} 10^{-6}\right)$ elemental data. Including all of Wayqecha samples produces a slight positive correlation between runoff and $\mathrm{Sr} / \mathrm{Na}$ (i.e. slopes of $38^{*} 10^{-6} \pm 26^{*} 10^{-6}$ and $36^{*} 10^{-6} \pm 25^{*} 10^{-6}$ for the corrected and uncorrected data respectively; Fig. 7b). For the San Pedro, MLC, and CICRA catchments, $\mathrm{Sr} / \mathrm{Na}$ ratios show a slight negative correlation with runoff and have slopes that are significantly different from zero for both the atmospheric-input corrected and uncorrected elemental data (Fig. 8b-10b). During the falling limb of wet-season storms in the CICRA catchment, $\mathrm{Sr} / \mathrm{Na}$ ratios are slightly elevated relative to the rising limb for both the atmospheric-input corrected and uncorrected elemental data (Fig. 10b). These falling limb samples also show elevated $\mathrm{Ca} / \mathrm{Na}$ ratios relative to all other samples collected at CICRA (Fig. 10a). At the other sites, $\mathrm{Ca} / \mathrm{Na}$ ratios are positively correlated with $\mathrm{Sr} / \mathrm{Na}$ ratios (Figs. 7a-10a).

\section{Discussion}

The variation in solute chemistry with runoff presented in this study is first used to identify specific processes that give rise to the variability seen between elements in each catchment. This discussion includes sections 4.1 and 4.2, where elemental ratio-runoff relationships are used to examine how changes in the contribution of solutes sourced from different lithologies and the precipitation of secondary mineral phases affect concentration-runoff relationships respectively. Possible mechanisms for the temporal variability in concentration runoff relationships observed at each of the sites (e.g., during storm events) are discussed in section 4.3. After the details of concentration-runoff and ratio-runoff relationships are discussed for each catchment, the concentration-runoff relationships for selected elements are compared between catchments in order to identify how coupled variation in geomorphic and hydrologic processes leads to differences in solute chemistry and chemical weathering (section 4.4). In section 4.5 , the implications of co-variation in the geomorphic and hydrologic controls on chemical weathering for the larger Andes/Amazon system are discussed.

\subsection{Lithologic controls on concentration-runoff and ratio-runoff relationships}

The observed variation in Sr/Na ratios with runoff at the San Pedro, MLC, and CICRA sites (Figs. 7b-10b) suggests that the relative contribution of silicate mineral dissolution to the dissolved load changes with runoff as observed at other sites (Gaillardet et al. 1999, Tipper at al. 2006, Qin et al. 2006, Calmels et al. 2011). Typically, silicate rocks are characterized by lower $\mathrm{Ca} / \mathrm{Na}$ and $\mathrm{Sr} / \mathrm{Na}$ ratios relative to carbonate rocks (Gaillardet et al. 1999). Thus, the slope of the Sr/Na ratio-runoff relationships at San Pedro, MLC, and CICRA implies that the relative proportion of solutes derived from silicate mineral dissolution increases with increasing runoff (Figs. 8b-10b). A similar, 
561 albeit weaker, relationship is also observed for $\mathrm{Ca} / \mathrm{Na}$ ratios (Figs. 8a-10a). The

562 differences between $\mathrm{Sr} / \mathrm{Na}$ and $\mathrm{Ca} / \mathrm{Na}$ ratios could reflect lithologic heterogeneity and/or

563

564

565

566

567

568

569

570

571

572

573

574

575

576

577

578

579

580

581

582

583

584

585

586

587

588

589

590

591

592

593

594

595

596

597

598

599

600

601

602

603

604

605

606

607

608

609

610 fluids will reach equilibrium with a secondary Si-bearing phase allowing $\mathrm{Na}$ and $\mathrm{Li}$
611 concentrations to increase relative to Si as water/rock interaction progresses (Figs. 7c,dpreferential biological Ca cycling (Blum et al. 2008).

Potentially, increases in the proportion of solutes derived from silicate mineral dissolution with increasing runoff could result from the carbonate reaction front being deeper than the silicate reaction front, as is observed in some settings (e.g., Brantley et al. 2013). As the water table rises above the carbonate reaction front at higher flow rates, the proportion of solutes derived from silicate weathering would increase (c.f. Godsey et al. 2009). Regardless of the exact mechanism, changes in the relative contributions of carbonate versus silicate weathering with runoff complicates the interpretation of the concentration-runoff relationships of $\mathrm{Ca}, \mathrm{Mg}$, and $\mathrm{Sr}$ because these elements are sourced from both silicate and carbonate minerals (Gaillardet et al. 1999). As a result, the rest of the discussion will focus on $\mathrm{Na}$, $\mathrm{Li}$, and $\mathrm{Si}$ because these elements are sourced only from silicate mineral dissolution in the studied catchments.

\subsection{The effects of secondary mineral formation on concentration-runoff and ratio-runoff relationships}

The power law exponent describing the relationship between Si concentrations and discharge is consistently higher than $\mathrm{Na}$ and $\mathrm{Li}$ at all sites despite the fact that all three elements have the same lithologic source (Figs. 11-12; Table 2, A7-8). The concentrations of $\mathrm{Si}$ also remain relatively constant between the sampling sites (Tables A1-4). Together, these observations suggest that Si concentrations are maintained by equilibrium with respect to a secondary silicate mineral, which is consistent with other hydrochemical studies (Clow and Mast 2010, Maher 2011). Independent evidence for near-equilibrium conditions comes from the observed variation in element/Si ratios with runoff (Figs. 7c,d-10c,d). During silicate mineral dissolution, both cations (e.g., Na and $\mathrm{Li})$ as well as $\mathrm{Si}$ are released into the dissolved phase. As dissolution progresses, saturation with respect to secondary silicates can buffer the concentration of dissolved $\mathrm{Si}$ while the concentrations of dissolved cations that are not readily partitioned into secondary silicates (e.g. Na) continue to increase. The removal of Si but not cations should lead to an increase in the element/Si ratio (e.g., Georg et al. 2007). Within this simple framework, it is possible to interpret intra-catchment variations in $\mathrm{Na} / \mathrm{Si}$ and $\mathrm{Li} / \mathrm{Si}$ with runoff as partly reflecting the balance between primary silicate mineral dissolution and secondary mineral precipitation, because $\mathrm{Na}$, Li, and $\mathrm{Si}$ are all sourced dominantly from silicate minerals.

In addition to primary silicate mineral dissolution, dissolved Si concentrations in rivers may also reflect the dissolution of highly reactive Si-bearing phases (e.g., biogenic opal; Derry et al. 2005). These reactive Si-bearing phases may decrease the amount of time required for dissolved $\mathrm{Si}$ concentrations to reach saturation. Nonetheless, changes in element/Si ratios likely reflect $\mathrm{Si}$ removal since the release of $\mathrm{Na}$ and Li from primary silicates will be accompanied by additional Si release. If solutions are buffered by highly reactive phases and near saturation, additional $\mathrm{Si}$ would be removed into secondary phases, and this process would influence the resulting dissolved element/Si ratio. Indeed, silicon isotope measurements in many systems (Georg et al. 2006, Georg et al. 2007, Cardinal et al. 2010, Fontorbe et al. 2013), including the Amazon system (Hughes et al. 2013), are consistent with the removal of Si from the dissolved load.

The general observation that $\mathrm{Na} / \mathrm{Si}$ and $\mathrm{Li} / \mathrm{Si}$ ratios decrease with increasing runoff is consistent with the river composition at low runoff being dominated by inputs from fluids with long transit times (i.e. groundwaters). After some threshold transit time, 
$10 c, d)$. As runoff increases, the proportion of fluids with shorter transit times likely

613

614

615

616

617

618

619

620

621

622

623

624

625

626

627

628

629

630

631

632

633

634

635

636

637

638

639

640

641

642

643

644

645

646

647

648

649

650

651

652

653

654

655

656

657

658

659

660 increases (Figs. 7c,d-10c,d). Since these fluids have had less time to react with minerals, $\mathrm{Na}$ and $\mathrm{Li}$ concentrations will have increased less relative to $\mathrm{Si}$, yielding lower element/Si ratios compared to the low runoff rate samples.

Relative to $\mathrm{Na}$, $\mathrm{Li}$ is more readily incorporated into secondary silicate phases (e.g., Huh et al. 2004). As a result, comparisons of the variation in $\mathrm{Na}$, $\mathrm{Li}$, and $\mathrm{Si}$ concentrations in each catchment can yield additional insight into secondary mineral formation processes and also inform our use of Li as a paleo-weathering proxy (e.g. Misra and Froelich 2012). If $\mathrm{Li}$ behaves as conservatively as $\mathrm{Na}$ (i.e. if neither element is incorporated significantly into secondary silicates), then there should be no relationship between $\mathrm{Na} / \mathrm{Si}$ and $\mathrm{Li} / \mathrm{Na}$ ratios in a given catchment. If $\mathrm{Li}$ is significantly incorporated into secondary silicates relative to $\mathrm{Na}$, then there should be a negative correlation between $\mathrm{Na} / \mathrm{Si}$ and $\mathrm{Li} / \mathrm{Na}$ ratios with a slope that reflects the affinity of $\mathrm{Li}$ for the secondary phase relative to $\mathrm{Na}$. In the Andean catchments (SP and Way), Li behaves as conservatively as $\mathrm{Na}$ (Way; Fig. 13) or is only slightly incorporated into secondary silicates (SP; Fig. 13). At the Andean outlet site (MLC), Li is slightly incorporated into secondary silicates (Fig. 13). In the foreland floodplain (CICRA), Li is strongly incorporated into secondary phases relative to $\mathrm{Na}$ (Fig. 13). Potentially, this behavior is related to a change in the composition of the dominant secondary silicate phase between the Andes and foreland-floodplain as suggested by downstream changes in the clay mineralogy of suspended sediments (Guyot et al. 2007). The changing behavior of Li relative to Na observed in the Madre de Dios system (this study) is consistent with recent studies of the adjacent Beni River, which show Li incorporation into secondary minerals across the mountain-floodplain transition based on Li isotope evidence (Dellinger et al. 2014, 2015).

\subsection{The effects of changes in fluid flow paths on concentration-runoff and ratio-runoff relationships}

While the general trends in $\mathrm{Na} / \mathrm{Si}$ and $\mathrm{Li} / \mathrm{Si}$ ratios with runoff are consistent with the conceptual framework presented in section 4.2 (i.e. at low runoff, fluid transit times are longer and fluids are at equilibrium with respect to a secondary Si-bearing phase allowing for $\mathrm{Na} / \mathrm{Si}$ and $\mathrm{Li} / \mathrm{Si}$ ratios to increase), some notable deviations occur (e.g., Figs. $7 \mathrm{c}, \mathrm{d}-10 \mathrm{c}, \mathrm{d})$. In the San Pedro catchment, elevated $\mathrm{Na} / \mathrm{Si}$ and Li/Si ratios are seen at both high and low runoff (Figs. $8 \mathrm{c} \& 8 \mathrm{~d}$ ). It is unlikely that this represents an additional input from a concentrated groundwater source at high runoff because the concentrationrunoff relationships for most elements during this period suggest dilution (i.e. power law slopes of the subordinate fits near -1; Fig. 4, Table 2, A7-8). Dilution at high runoff may be caused by a shift towards fast, near surface flow paths with reduced water-rock interaction time, as suggested by Stallard and Murphy (2014) to explain the dilution in dissolved organic carbon at high runoff in streams in Puerto Rico, although they did not see the same dilution of other elements (e.g., $\mathrm{Na}$ and $\mathrm{Si}$ ), which we see in the SP catchment. Nonetheless, a switch to fast, near-surface flow paths at SP is consistent with the observation from this site that the fraction of particulate organic carbon derived from recently living biomass also increases at high runoff rates, because the erosion of surface soils by fast, near surface flow would be expected to mobilize modern particulate organic carbon (Clark et al. 2013, Clark 2014).

Our observation from the SP catchment that $\mathrm{K}$ concentrations increase with increasing runoff at runoff rates $>12 \mathrm{~mm} /$ day rates despite the overall trend of dilution for other solutes is also consistent with a shift to fast, near-surface flow paths (Table $1, \mathrm{~A} 2$ ). Potassium can be enriched in surface soil layers because it is present as an

661 exchangeable cation and/or in biomass at relatively high concentrations (Elsenbeer et al.

662 1995, Boy et al. 2008). At high runoff, Li concentrations are also elevated (Fig. 4c), but a 
663 potential source of the Li enrichment is hard to identify because $\mathrm{Li}$ is not taken up

664 appreciably by plants (Lemarchand et al. 2010). Li could be derived from clay mineral

665

666

667

668

669

670

671

672

673

674

675

676

677

678

679

680

681

682

683

684

685

686

687

688

689

690

691

692

693

694

695

696

697

698

699

700

701

702

703

704

705

706

707

708

709

710

711

712 dissolution and though this should also release $\mathrm{Si}$, plant uptake may remove Si from soil solutions (Derry et al. 2005). It is also possible that $\mathrm{Li}$ is enriched in the surface-soil exchange pool and/or preferentially leached during mineral dissolution. Involvement of the surface-soil exchange pool is consistent with the rapid change in Li concentrations (i.e. exchange reactions occur rapidly; Clow and Mast 2010, Kim et al. 2014) and the fact that elevated Li concentrations are not sustained.

Reactive transport through a uniform mineral substrate would not generate the complex behavior in concentration-runoff and ratio-runoff relationships seen at SP. Instead, it is likely that the dominant fluid flow paths at SP vary in response to runoff, as outlined schematically in Fig. 14. Because this complex behavior occurs at high runoff rates, it has an important impact on the total solute fluxes. Compared to the other sites, San Pedro has the highest annual precipitation (Lambs et al. 2012, Clark et al. 2014), which may be a factor contributing to its unique behavior at high runoff.

Similar to the SP catchment, the observed variation in $\mathrm{Li} / \mathrm{Si}$ with runoff at MLC cannot be described by a single trend, as minima are present at both high and low runoff (Fig. 9). At low runoff, the decrease in in the Li/Si ratio is associated with the dilution of $\mathrm{Li}$ during dry season storms (Figs. $5 \mathrm{c}$ and $9 \mathrm{~d}$ ). Dilution of Li would be expected if Li-bearing primary phases were depleted in the sediments accessed by dry season storm flow paths. This is consistent with the overall trend of decreasing Li concentrations with elevation, which suggests the preferential loss of Li-bearing phases. At high runoff, lower $\mathrm{Li} / \mathrm{Si}$ ratios are consistent with shorter fluid transit times favoring less sequestration of $\mathrm{Si}$ in secondary phases (see section 4.1.4).

During the falling limb of wet season storms, samples from the CICRA catchment show elevated concentrations for some solutes (Fig. 6, Table A4) as well as elevated $\mathrm{Ca} / \mathrm{Na}$ ratios (Fig. 10a). This behavior could stem from either temporal variability in the relative contributions of different tributaries or a catchment-scale change in the dominant fluid flow paths. While these possibilities cannot be distinguished with the available data, the coupled increase in the $\mathrm{Ca} / \mathrm{Na}$ ratio suggests increased inputs from the dissolution of carbonate minerals (Gaillardet et al. 1999, Figs. 10d).

At the Wayqecha site, the river chemistry shows a bimodal behavior with samples showing two distinct modes of solute concentrations and $\mathrm{Sr} / \mathrm{Na}$ ratios (Figs. $3,7 b$; Table A1). However, unlike the other sites, there appears to be no clear temporal or hydrologic control on the shift between the two distinct solute chemistries. The Wayqecha sampling locality is immediately downstream from a confluence of two streams. It is possible that the variation in the solute chemistry reflects changes in the mixing proportions of the two streams, because the west tributary typically shows higher $\mathrm{Sr} / \mathrm{Na}$ ratios and solute concentrations (Table A1). For example, the mixing proportions of the two streams may vary in response to changes in the spatial distribution of precipitation within the catchment, leading to variable trends in $\mathrm{Sr} / \mathrm{Na}$.

\subsection{Geomorphic control on concentration-runoff relationships in the Andes Amazon system}

The power law exponents that relate elemental concentrations and runoff in eq. 1 for both the total and dominant fits decrease with decreasing mean catchment elevation and mean catchment slope angle (Figs. 11-12). This behavior is true for all elements with concentrations that are highly correlated with runoff (i.e. excluding $\mathrm{Cl}^{-}$and $\mathrm{K}$ for most catchments) as well as for both the atmospheric-input corrected and uncorrected data (Figs. 11-12). In the following discussion, we focusing on $\mathrm{Na}$ and $\mathrm{Si}$, because they

713 are major elements sourced only from silicate mineral dissolution (see section 4.1; Fig. 
714 12). For both the total and dominant fits with and without input atmospheric correction,

715 the exponents for $\mathrm{Na}$ and $\mathrm{Si}$ calculated for the Andean sites (Way and SP) do not overlap with the foreland floodplain site (CICRA) within their respective $95 \%$ confidence intervals (Fig. 12, Table 2). While the exact magnitude of the difference between the Andean and foreland floodplain sites is sensitive to how we fit the data with eq. 1 (Fig. 11-12), the broad trend of decreasing power law exponent with decreasing mean catchment slope angle is preserved regardless of how the data are treated.

The observed correlation between the power law exponents and mean catchment slope angle, independent of how the data are corrected, implies that the hydrologic control on chemical weathering fluxes (i.e. the concentration-runoff relationship) is related to the geomorphic regime as reflected in the measurement of mean catchment slope angle. The observed range of the power-law exponents for $\mathrm{Na}$ and $\mathrm{Si}$ in the Andes-Amazon system (Figs. 11-12, Table 2, A7-8) is comparable to the range seen in compilations of data from U.S. streams (Godsey et al. 2009) and global rivers (Moon et al. 2014). The surface areas of the catchments included in this study are generally greater than those in the U.S. stream compilation (Godsey et al. 2009) and smaller than those in the global river compilation (Moon et al. 2014).

The results of this study show that the relationship between solute concentrations and runoff varies markedly between the Andean and foreland floodplain sites (Figs. 1112). Previous research in catchment hydrology and geochemistry has suggested multiple mechanisms that could produce concentration-runoff relationships (e.g., Johnson et al. 1969, Christophersen et al. 1990, Godsey et al. 2009; Maher 2011; Maher and Chamberlain 2014). Of these models, the solute production model (Maher 2011, Maher and Chamberlain 2014) and the porosity-permeability-aperture model (PPA model; Godsey et al. 2009) produce functional forms that are consistent with field data and include internally consistent parameter values (Godsey et al. 2009, Maher 2011, Maher and Chamberlain 2014). While the available formulations of these models make many assumptions that may be inconsistent with natural systems, the underlying processes that they describe are likely to be important. As a result, qualitative comparisons between model predictions and field data can be useful. The relevant details of the solute production model and PPA model are included below and are then followed by a discussion of how key model parameters may vary between the AndesAmazon sites and give rise to the observed change in the power law exponent with the geomorphic regime.

In the solute production model, the reaction kinetics and the abundance of primary reactive minerals set the timescale required for solute concentrations to approach the thermodynamic equilibrium concentration (i.e. the solute concentration where either the primary mineral is in equilibrium with the fluid or there is a balance between the rates of primary mineral dissolution and secondary mineral precipitation; Maher 2011, Maher and Chamberlain 2014). If fluid transit times are long relative to the timescale required to approach equilibrium, the catchment will display chemostatic behavior (Maher 2011; Maher and Chamberlain 2014). If fluid transit times are short relative to the timescale required to approach equilibrium, then the catchment will show dilution. High rates of erosion can increase the abundance of primary reactive minerals by shortening mineral residence times (Gabet and Mudd, 2009, Ferrier and Kirchner 2008; Hilley et al. 2010, West 2012, Li et al. 2014, Maher and Chamberlain 2014). While this means that fluids will quickly approach equilibrium in rapidly eroding environments, high solute fluxes will only be observed if fluid transit times are sufficiently long (Maher 2011, Maher and Chamberlain 2014). Rapid erosion is associated with high relief (Montgomery and Brandon, 2002), and high relief may also contribute to increasing flow

764 path lengths and fluid transit times (McGuire et al. 2005). However, available data do not 
support a singular effect of topography on fluid transit times (McGuire et al. 2005, Tetzlaff et al. 2009).

If the porosity, permeability, and average pore aperture of the critical zone decays exponentially with depth, then the mineral surface area in contact with fluids will increase as the water table rises. Depending upon the length scales over which porosity, permeability, and average pore aperture decrease exponentially with depth, the increase in the available surface area with runoff will variably offset the increased water flux leading to a power-law scaling between concentration and runoff (Godsey et al. 2009). If the length scales over which porosity, permeability, and average pore aperture decrease exponentially with depth are such that the available surface area increases significantly as the water table rises (i.e. a heterogeneous critical zone), then the system will be more "chemostatic." If the length scales over which porosity, permeability, and average pore aperture decrease exponentially with depth are such that the available surface area does not increase significantly as the water table rises (i.e. a more homogeneous critical zone), then the system will dilute to a greater extent with increasing runoff. However, as noted by Godsey et al. (2009), the depth-dependent variation in primary mineral abundances must also factor in as it also controls the mineral surface area available for reaction.

\subsubsection{Fluid transit times as a possible control on concentration-runoff relationships}

The systematic variation in the calculated power law exponent with mean catchment slope angle (Figs. 11-12) suggests that an underlying control on the concentration-runoff relationship of each catchment is somehow related to topography and/or erosional regime. As is often the case in natural gradients, multiple environmental factors co-vary with mean catchment slope angle in our study area. One potential driver might be differences in fluid transit times (i.e. the time it takes rainfall to transit through the catchment and enter the stream channel) between the sites. Changes in the fluid transit time could modulate the concentration-runoff relationship by influencing the length of time available for solute concentrations to approach the thermodynamic equilibrium concentration (Maher 2010; Maher 2011; Maher and Chamberlain 2014).

At present, there are few direct constraints on fluid transit times in any of the studied catchments, but there is some relevant evidence from catchment water balances and temporal variations in the water isotopic composition of rainwater and river flow. Analysis of the monthly water budgets of the Way and SP catchments suggests that precipitation delivered during the wet season (December-March) is transiently stored within the catchment and discharged during the dry season (May-September; Clark et al. 2014). While the isotopic composition of precipitation shows a large seasonal cycle (i.e. amplitude of $\sim 70 \%$ in $\delta \mathrm{D}$ ), the isotopic composition of the river remains relatively constant (i.e. amplitude of $\sim 10 \%$ in $\delta \mathrm{D}$; Clark et al. 2014). There exist many complex models for quantitatively interpreting this isotopic dampening in terms of mean fluid transit times (e.g. McGuire and McDonnell 2006), all indicate that the extent of dampening is inversely proportional to the relative contribution of water with short fluid transit times. Thus, the seasonal water budget and the large extent of isotopic dampening in the Way and SP catchments imply relatively long fluid transit times.

Seasonal measurements of tributaries across the elevational gradient show that at lower elevations, the stream waters are more sensitive to seasonal changes in the isotopic composition of precipitation (i.e. less isotopic dampening at lower elevation; Ponton et al. 2014). This implies that fluids with shorter transit times make a greater contribution to stream flow at lower elevations (i.e. CICRA catchment). Although there is not enough data to constrain the mean and distribution of fluid transit times robustly, 
especially at CICRA, the existing data are consistent with a increase in the proportion of

817

818

819

820

821

822

823

824

825

826

827

828

829

830

831

832

833

834

835

836

837

838

839

840

841

842

843

844

845

846

847

848

849

850

851

852

853

854

855

856

857

858

859

860

861

862

863

864

865 fluids with short transit times with decreasing mean catchment slope angle. This difference in fluid transit times may partly explain the observed decrease in the power law exponent with decreasing mean catchment slope angles (Figs. 11-12). For the same net reaction rates, a greater relative contribution of fluids with shorter transit times in the foreland floodplain would result in greater solute dilution with increasing runoff (i.e. lower power law exponent), because the time available for reaction would be shorter (Maher 2010, Maher 2011, Maher and Chamberlain 2014).

\subsubsection{Mineral residence times as a possible control on power law exponents}

Changes in concentration-runoff relationships between the sites may also be related to changes in mineral residence times (i.e. the duration of time minerals spend weathering in the critical zone before being exported by erosion). Because the Andes Mountains are the dominant source of sediments in the Amazon system (Gibbs 1967), there is a timescale associated with the transport of material to and through the foreland floodplain regions (Dosseto et al. 2006; Bouchez et al. 2012). At the river basin scale, this timescale can be considered the residence time of minerals within the critical zone. As material is transported, it undergoes reaction and becomes increasingly depleted in primary reactive minerals. If the timescale associated with sediment transfer from the Andes through the foreland floodplain is sufficiently long, then this would lead to a depletion of primary reactive minerals and increase the time required for fluids to reach thermodynamic equilibrium in the foreland floodplain (Maher and Chamberlain 2014). All else being equal, a longer time-to-equilibrium should result in greater solute dilution with increasing runoff (Maher and Chamberlain 2014). Because fluids with short transit times are thought to make a greater contribution to river flow in the foreland floodplain (see section 4.4.1), the effect of an increase in the time required to reach equilibrium on the concentration-runoff relationship is amplified leading to even greater solute dilution. Across a similar elevation gradient in the adjacent Bolivian Andes, U-series analyses suggest an increase in sediment residences times with decreasing elevation (Dosseto et al. 2006). If residence times vary with elevation in a similar fashion in the Kosñipata-Madre de Dios system and lead to depletion in primary mineral concentrations, then this could be a plausible mechanism to cause the observed change in the concentration-runoff relationship with elevation.

\subsubsection{Fluid flow paths and weathering zone thickness as a possible controls concentration-runoff relationships}

The thickness of the weathering zone (i.e. the region bounded by the top of the soil profile and the depth of unaltered bedrock) is thought to influence the concentrationrunoff relationship by defining the length scale over which reactions occur and, for a given flow rate, the fluid transit time (Maher 2011, Maher and Chamberlain 2014). Longer weathering length scales, or "deeper" weathering zones, would lead to higher power law exponents and favor "chemostatic" behavior (Maher 2011, Maher and Chamberlain 2014). Some models (e.g. Gabet and Mudd 2009) assume that weathering reactions only occur in soils and regolith and that the thickness of this weathering zone is inversely related to erosion rates (Lebedeva et al. 2007). In the Andes-Amazon system, erosion rates are higher in the Andes Mountains (Gibbs 1967, Meade 1985) and, globally, erosion rates are correlated with mean catchment slope angle (Portenga and Bierman 2011, Larsen et al. 2014). Together, these observations would suggest that the weathering zone would be deeper in the foreland floodplain catchment relative to the Andean catchments leading to higher power law exponent values (i.e. "chemostatic" 
behavior) in the foreland floodplain catchment, which is the opposite of what is observed (Figs. 11-12).

In contrast to an inverse relationship between weathering zone thickness and erosion rates, global datasets are best explained if the thickness of the weathering zone does not vary considerably with erosion (West 2012). If the depth of the weathering zone is relatively constant, a significant proportion of the weathering zone at high erosion sites with thin soils is expected to be within fractured bedrock. Indeed, hydrologic and hydrochemical studies from other regions conclude that the depth of the hydrologically and chemically active weathering zone in steep mountain catchments, often dominated by sedimentary or metamorphic lithologies, extends into fractured bedrock (Anderson et al. 1997; Tipper et al. 2006; Calmels et al. 2011; Andermann et al. 2012; Salve et al. 2012; Clark et al. 2014; Kim et al. 2014). In the Andean sites in this study (Way and SP), the annual water budget and water isotope mixing calculations suggest that significant volumes of water transit through fractured bedrock before entering the stream channel (Clark et al. 2014). Thus, it is possible that some of the observed changes in the concentration-run off relationships are related to the fact that a greater proportion of the flow path length in the Andean catchments is contained within fractured bedrock, which has a higher concentration of weatherable minerals than soils and regolith. By increasing the fraction of weatherable minerals, these bedrock flow paths would be expected to approach thermodynamic equilibrium more rapidly leading to chemostatic behavior (Maher 2011; Maher and Chamberlain 2014). The role of weathering in fractured bedrock (potentially with abundant primary minerals) may be inherently related to increased fluid transit times (because of longer length scales), but it is not straightforward to disentangle the effects of reactive mineral availability verses fluid transit times based on the time-series data from this study. Targeted work to better understand the dominant flow paths that contribute solutes to river systems in the Andes-Amazon and other systems would be useful future contributions to the study of chemical weathering. In particular, simultaneous time-series analysis of solute concentrations in soil pore waters, groundwaters, and/or first order tributaries are likely to greatly enhance our interpretation of riverine measurements.

\subsubsection{Critical zone structure as a possible control on power law exponents}

In the framework of the PPA model, the observed decrease in the power law exponent with mean catchment slope angle could result from changes in the structure of the critical zone. In the foreland floodplain, thick deposits of Andean sediments (10-50 $\mathrm{m}$; Rigsby et al. 2009) may give rise to a critical zone where changes in the depth of the water table do not lead to substantial changes in reactive surface area. Coupled with primary mineral depletion as a result of long mineral residence times (Dosseto et al. 2006), these characteristics of the critical zone in the foreland floodplain would give rise to system where concentrations dilute with increasing runoff. In the Andean catchments, bedrock fractures may provide most of the reactive surface area (Clark et al. 2014). As a result, it is difficult to predict how the reactive surface area changes with water table depth in the Andean catchments.

\subsection{Implications for the role of floodplain weathering in the Amazon system}

The role of the foreland floodplain in the overall Amazonian weathering budget has important implications for understanding of how weathering processes operate at a global scale (Bouchez et al. 2012). Currently, models that couple the effects of mineral dissolution kinetics and erosion within a framework of geomorphic steady state (e.g., Gabet and Mudd 2009; Hilley et al. 2010; West 2012) consider the time that minerals spend within upland, eroding catchments, but not the time spent in transit through 
917 lowland floodplains. Similarly, models linking fluid chemistry and erosion rates (e.g., Li et

918 al. 2014; Maher and Chamberlain, 2014) consider an eroding column developed from

919

920

921

922

923

924

925

926

927

928

929

930

931

932

933

934

935

936

937

938

939

940

941

942

943

944

945

946

947

948

949

950

951

952

953

954

955

956

957

958

959

960

961

962

963

964

965 bedrock. Arguably, the transport and deposition of reactive sediments in floodplains constitutes a distinct physical mechanism where reactive material is supplied to the top of the weathering column as opposed to being supplied from below as is commonly modeled, although the dynamics of storage and re-working of sediments within floodplains adds complexity (e.g., Bradley and Tucker 2013). If the weathering flux supplied to the ocean as a result of mountain uplift is dominantly the result of material supply to floodplains, then additional factors need to be considered to model these effects over geologic timescales.

The observation that the power law exponent relating concentration and runoff decreases with decreasing mean catchment slope angle has important implications for weathering processes in the foreland floodplain region (Figs. 11-12). Solute concentrations in the foreland floodplain region show more dilution than in the Andes, meaning that the corresponding weathering fluxes are relatively insensitive to changes in runoff over seasonal timescales (Figs. 3-6; Table 1). This contrasts with the Andean catchments, which show a near 1:1 relationship between flux and runoff, implying a high sensitivity to changes in hydrologic conditions (Figs. 3-6; Table 1). This is broadly consistent with the hypothesis that rapidly eroding environments are more sensitive to changes in runoff relative to more slowly eroding environments (e.g., West 2012; Maher and Chamberlain 2014). However, it is worth stressing that our results characterize the sensitivity of chemical weathering fluxes to seasonal changes in runoff. While seasonal concentration-runoff relationships can be stationary over inter-annual and decadal timescales (Godsey et al. 2009, Eiriksdottir et al. 2013) and have previously been interpreted to provide insight into the climatic control on chemical weathering reactions (e.g. Tipper et al. 2006, Eiriksdottir et al. 2013), our dataset does not technically constrain the climatic sensitivity (sensu Stocker et al. 2013) of chemical weathering fluxes in the Andes-Amazon system.

The general model of supply vs. kinetically limited weathering regimes suggests that when weathering fluxes are limited by the supply of material by erosion, they are less sensitive to changes in temperature (West et al. 2005, West 2012) and runoff (West et al. 2005, West 2012, Maher and Chamberlain 2014). While our results provide no constraints on the temperature or erosional dependence of foreland floodplain weathering fluxes, the lack of a significant runoff dependence is consistent with supply limitation in the foreland floodplain (West et al. 2005, West 2012, Maher and Chamberlain 2014).

\section{CONCLUSIONS}

The results of this study show that the relationship between solute concentrations and runoff varies systemically with mean catchment slope angle across a mountain-tofloodplain transition in the Peruvian Amazon. Catchments with steep mean catchment slope angles in the Andes Mountains are more "chemostatic" relative to catchments with more shallow mean catchment slope angles in the foreland floodplain. These observations provide new empirical data indicating an important link between physical erosion processes and hydrology in controlling catchment-scale weathering fluxes ( $\mathrm{Li}$ et al. 2014, Maher and Chamberlain 2014). Within each of the studied catchments, variability in the concentration-runoff and ratio-runoff relationships suggests that changes in lithologic sources, secondary reactions, and, potentially, the dominant fluidflow paths play an important second-order role in controlling solute chemistry. In

966 particular, variations in $\mathrm{Na} / \mathrm{Si}$, $\mathrm{Li} / \mathrm{Si}$ and $\mathrm{Sr} / \mathrm{Na}$ ratios with runoff imply systematic 
changes in secondary silicate mineral precipitation and the proportion of cations sourced from primary silicate minerals with runoff.

It is likely that combined variation in fluid transit times and mineral residence times gives rise to the variation in concentration-runoff and ratio-runoff relationships observed across the Andes to foreland floodplain gradient (Fig. 15). It remains out of reach with the current data to quantitatively separate the relative roles of fluid transit times and mineral residence times, and to understand to what extent these are inherently linked within the Andes-Amazon system. However, the observations from this study emphasize that more detailed information about the timescales associated with fluid and sediment transport, and how they relate, may provide key information about weathering processes globally. One implication of the observed variation in the link between runoff and weathering fluxes is that the Andes are more sensitive to changes in runoff than the foreland floodplain region (Figs. 11,12,15). This is consistent with previous global models and suggests an important role for active erosion in global climate-weathering feedbacks, and in the global weathering thermostat (West 2012; Maher and Chamberlain 2014).

\section{Acknowledgements}

Financial support for this research was provided by NSF EAR-1227192 to A.J. West. K. Clark was supported by the Natural Sciences and Engineering Research Council of Canada (NSERC) and Clarendon Fund PhD scholarships. M. Torres was supported by USC College doctoral and C-DEBI fellowships. We thank ACCA Peru (Wayqecha, CICRA), Incaterra (San Pedro), and CREES (MLC) for field support; Arturo Robles Caceres, J.A. Gibaja Lopez, J. Huamán Ovalle, R.J. Abarca Martínez, I. Cuba Torres, A. Alfaro-Tapia, D. Oviedo Licona, and J. Farfan Flores for field assistance; and Julien Bouchez, Jotautas Baronas, and James Kirchner for helpful discussions prior to submission. Two anonymous reviewers and Julien Bouchez are acknowledged for their constructive criticism of an earlier version of this manuscript.

\section{References}

Andermann C., Longuevergne L., Bonnet S., Crave A., Davy P. and Gloaguen R. (2012) Impact of transient groundwater storage on the discharge of Himalayan rivers. Nat. Geosci. 5, 127132.

Anderson S. P., Dietrich W. E., Torres R., Montgomery D. R. and Loague K. (1997) Concentration-discharge relationships in runoff from a steep, unchanneled catchment. Water Resour. Res. 33, 211.

Andreae M., Talbot R., Berresheim H. and Beecher K. (1990) Precipitation chemistry in central Amazonia. J. Geophys. Res. 95, 16987-16999.

Asner G. P., Anderson C. B., Martin R. E., Knapp D. E., Tupayachi R., Sinca F. and Malhi Y. (2014) Landscape-scale changes in forest structure and functional traits along an Andes-toAmazon elevation gradient. Biogeosciences 11, 843-856.

Ballew N. (2011) Quantifying discharge in the Kosñipata-Madre de Dios river system, Peru. University of Southern California.

Beaulieu E., Goddéris Y., Donnadieu Y., Labat D. and Roelandt C. (2012) High sensitivity of the continental-weathering carbon dioxide sink to future climate change. Nat. Clim. Chang. 2, 346-349. 
1013 Berner R. A., Lasaga A. C. and Garrels R. M. (1983) The Carbonate-Silicate Geochemical Cycle

1014

1015

1016

1017

1018

1019

1020

1021

1022

1023

1024

1025

1026

1027

1028

1029

1030

1031

1032

1033

1034

1035

1036

1037

1038

1039

1040

1041

1042

1043

1044

1045

1046

1047

1048

1049 And Its Effect on Atmospheric Carbon Dioxide Over the Past 100 Million Years. Am. J. Sci. 283, 641-683.

Beven K. J. (2011) Rainfall-runoff modelling: the primer., John Wiley \& Sons.

Blum J. D., Dasch A. a., Hamburg S. P., Yanai R. D. and Arthur M. a. (2008) Use of foliar Ca/Sr discrimination and $87 \mathrm{Sr} / 86 \mathrm{Sr}$ ratios to determine soil Ca sources to sugar maple foliage in a northern hardwood forest. Biogeochemistry 87, 287-296.

Bluth G. J. S. and Kump L. R. (1994) Lithologic and climatologic controls of river chemistry. Geochim. Cosmochim. Acta 58, 2341-2359.

Bonell M. and Gilmour D. A. (1978) The development of overland flow in a tropical rainforest catchment. J. Hydrol. 39, 365-382.

Bouchez J., von Blanckenburg F. and Schuessler J. a. (2013) Modeling novel stable isotope ratios in the weathering zone. Am. J. Sci. 313, 267-308.

Bouchez J., Gaillardet J., Lupker M., Louvat P., France-Lanord C., Maurice L., Armijos E. and Moquet J.-S. (2012) Floodplains of large rivers: Weathering reactors or simple silos? Chem. Geol. 332-333, 166-184.

Boy J., Valarezo C. and Wilcke W. (2008) Water flow paths in soil control element exports in an Andean tropical montane forest. Eur. J. Soil Sci. 59, 1209-1227.

Bradley D. N. and Tucker G. E. (2013) The storage time, age, and erosion hazard of laterally accreted sediment on the floodplain of a simulated meandering river. J. Geophys. Res. Earth Surf. 118, 1308-1319.

Brantley S. L., Lebedeva M. and Bazilevskaya E. (2014) Relating Weathering Fronts for Acid Neutralization and Oxidation to pCO2 and pO2. In Treatise on Geochemistry: Second Edition Elsevier Ltd. pp. 327-352.

Calmels D., Gaillardet J., Brenot A. and France-Lanord C. (2007) Sustained sulfide oxidation by physical erosion processes in the Mackenzie River basin: Climatic perspectives. Geology 35, 1003-1006.

Calmels D., Galy A., Hovius N., Bickle M., West A. J., Chen M. and Chapman H. (2011) Contribution of deep groundwater to the weathering budget in a rapidly eroding mountain belt, Taiwan. Earth Planet. Sci. Lett. 303, 48-58.

Cardinal D., Gaillardet J., Hughes H. J., Opfergelt S. and André L. (2010) Contrasting silicon isotope signatures in rivers from the congo basin and the specific behaviour of organic-rich waters. Geophys. Res. Lett. 37, 1-6.

Carlotto Caillaux V. S., Rodriguez G., Fernando W., Roque C., Dionicio J. and Chávez R. (1996) Geología de los cuadrángulos de Urubamba y Calca., Instituto Geológica Nacional, Lima, Peru.

Chadwick O., Derry L. and Vitousek P. (1999) Changing sources of nutrients during four million years of ecosystem development. Nature 397, 491-497. 

streamwater chemistry as a mixture of soilwater end-members - A Step Towards SecondGeneration Acidification Models. J. Hydrol. 116, 307-320.

1053

1054

1055

1056

1057

1058

1059

1060

1061

1062

1063

1064

1065

1066

1067

1068

1069

1070

1071

1072

1073

1074

1075

1076

1077

1078

1079

1080

1081

1082

1083

1084

1085

1086

1087

Clark K. E. (2014) Patterns and Drivers of Riverine Particulate Organic Carbon Transport in an Andean Valley. University of Oxford.

Clark K. E., Hilton R. G., West A. J., Malhi Y., Gröcke D. R., Bryant C. L., Ascough P. L., Robles Caceres A. and New M. (2013) New views on "old" carbon in the Amazon River: Insight from the source of organic carbon eroded from the Peruvian Andes. Geochemistry, Geophys. Geosystems 14, 1644-1659.

Clow D. W. and Mast M. A. (2010) Mechanisms for chemostatic behavior in catchments: Implications for CO2 consumption by mineral weathering. Chem. Geol. 269, 40-51.

Dellinger M., Gaillardet J., Bouchez J., Calmels D., Galy V., Hilton R. G., Louvat P. and FranceLanord C. (2014) Lithium isotopes in large rivers reveal the cannibalistic nature of modern continental weathering and erosion. Earth Planet. Sci. Lett. 401, 359-372.

Dellinger M., Gaillardet J., Bouchez J., Calmels D., Louvat P., Dosseto A., Gorge C., Alanoca L. and Maurice L. (2015) Riverine Li isotope fractionation in the Amazon River basin controlled by the weathering regimes. Geochim. Cosmochim. Acta.

Derry L. A., Kurtz A. C., Ziegler K. and Chadwick O. A. (2005) Biological control of terrestrial silica cycling and export fluxes to watersheds. Nature 433, 728-731.

Dixon J. L. and von Blanckenburg F. (2012) Soils as pacemakers and limiters of global silicate weathering. Comptes Rendus Geosci. 344, 597-609.

Dosseto A., Bourdon B., Gaillardet J., Maurice-Bourgoin L. and Allègre C. J. (2006) Weathering and transport of sediments in the Bolivian Andes: Time constraints from uranium-series isotopes. Earth Planet. Sci. Lett. 248, 759-771.

Dunne T. (1978) Field studies of hillslope flow processes. Hillslope Hydrol. 227, 293.

Eiriksdottir E. S., Gislason S. R. and Oelkers E. H. (2013) Does temperature or runoff control the feedback between chemical denudation and climate? Insights from NE Iceland. Geochim. Cosmochim. Acta 107, 65-81.

Elsenbeer H., Lack A. and Cassel K. (1995) Chemical fingerprints of hydrological compartments and flow paths and La Cuenca, western Amazonia. Water Resour. Res. 31, 3051-3058.

Ferrier K. L. and Kirchner J. W. (2008) Effects of physical erosion on chemical denudation rates: A numerical modeling study of soil-mantled hillslopes. Earth Planet. Sci. Lett. 272, 591-599.

Fontorbe G., De La Rocha C. L., Chapman H. J. and Bickle M. J. (2013) The silicon isotopic composition of the Ganges and its tributaries. Earth Planet. Sci. Lett. 381, 21-30.

Furch K. (1984) Water chemistry of the Amazon basin: the distribution of chemical elements among freshwaters. In The Amazon Springer. pp. 167-199.

Gabet E. J., Edelman R. and Langner H. (2006) Hydrological controls on chemical weathering rates at the soil-bedrock interface. Geology 34, 1065. 
Gabet E. J. and Mudd S. M. (2009) A theoretical model coupling chemical weathering rates with denudation rates. Geology 37, 151-154.

Gaillardet J., Dupre B., Allegre C. J. and Négrel P. (1997) Chemical and physical denudation in the Amazon River Basin. Chem. Geol. 142, 141-173.

Gaillardet J., Dupré B., Louvat P. and Allegre C. J. (1999) Global silicate weathering and CO2 consumption rates deduced from the chemistry of large rivers. Chem. Geol. 159, 3-30.

Gaillardet J., Rad S., Rivé K., Louvat P., Gorge C., Allègre C. J. and Lajeunesse E. (2011) Orography-driven chemical denudation in the lesser antilles: Evidence for a new feed-back mechanism stabilizing atmospheric CO 2. Am. J. Sci. 311, 851-894.

Galy A. and France-Lanord C. (1999) Weathering processes in the Ganges-Brahmaputra basin and the riverine alkalinity budget. Chem. Geol. 159, 31-60.

Georg R. B., Reynolds B. C., Frank M. and Halliday A. N. (2006) Mechanisms controlling the silicon isotopic compositions of river waters. Earth Planet. Sci. Lett. 249, 290-306.

Georg R. B., Reynolds B. C., West A. J., Burton K. W. and Halliday A. N. (2007) Silicon isotope variations accompanying basalt weathering in Iceland. Earth Planet. Sci. Lett. 261, 476490.

Godsey S., Kirchner J. and Clow D. (2009) Concentration-discharge relationships reflect chemostatic characteristics of US catchments. Hydrol. Process. 1864, 1844-1864.

1115 Graham R. C., Rossi A. M. and Hubbert K. R. (2010) Rock to regolith conversion: Producing hospitable substrates for terrestrial ecosystems. GSA Today 20, 4-9.

Guyot J. L., Jouanneau J. M., Soares L., Boaventura G. R., Maillet N. and Lagane C. (2007) Clay mineral composition of river sediments in the Amazon Basin. Catena 71, 340-356.

Hartmann J., Jansen N., Dürr H. H., Kempe S. and Köhler P. (2009) Global CO2-consumption by chemical weathering: What is the contribution of highly active weathering regions? Glob. Planet. Change 69, 185-194.

1125 Huasco W. H., Girardin C. a. J., Doughty C. E., Metcalfe D. B., Baca L. D., Silva-Espejo J. E., 1126 Cabrera D. G., Aragão L. E. O. C., Davila A. R., Marthews T. R., Huaraca-Quispe L. P., 
1127

1128

1129

1130

1131

1132

1133

1134

1135

1136

1137

1138

1139

1140

1141

1142

1143

1144

1145

1146

1147

1148

1149

1150

1151

1152

1153

1154

1155

1156

1157

1158

1159

1160

1161

1162

1163

1164

1165

Alzamora-Taype I., Mora L. E., Farfán-Rios W., Cabrera K. G., Halladay K., Salinas-Revilla N., Silman M. R., Meir P. and Malhi Y. (2014) Seasonal production, allocation and cycling of carbon in two mid-elevation tropical montane forest plots in the Peruvian Andes. Plant Ecol. Divers. 7, 125-142.

Huh Y., Chan L.-H. and Chadwick O. a. (2004) Behavior of lithium and its isotopes during weathering of Hawaiian basalt. Geochemistry, Geophys. Geosystems 5, 1-22.

INGEMMET (2013) GEOCATMIN - Geologia integrada por proyectos regionales., Instituto Geológico Minero Metalúrgico Lima, Peru,

Jarvis A., Reuter H. I., Nelson A., Guevara E. and others (2008) Hole-filled SRTM for the globe Version 4. available from CGIAR-CSI SRTM 90m Database (http//srtm. csi. cgiar. org).

Johnson N., Likens G., Bormann F., Fisher D. and Pierce R. (1969) A Working Model for the Variation in Stream Water Chemistry at the Hubbard Brook Experimental Forest, New Hampshire. Water Resour. Res. 5, 1353-1363.

Kim H., Bishop J. K. B., Dietrich W. E. and Fung I. Y. (2014) Process dominance shift in solute chemistry as revealed by long-term high-frequency water chemistry observations of groundwater flowing through weathered argillite underlying a steep forested hillslope. Geochim. Cosmochim. Acta 140, 1-19.

Kirchner J. W. and Neal C. (2013) Universal fractal scaling in stream chemistry and its implications for solute transport and water quality trend detection. Proc. Natl. Acad. Sci.

Kurtz A. C., Lugolobi F. and Salvucci G. (2011) Germanium-silicon as a flow path tracer: Application to the Rio Icacos watershed. Water Resour. Res. 47, W06516.

Lambs L., Horwath A., Otto T., Julien F. and Antoine P.-O. (2012) Isotopic values of the Amazon headwaters in Peru: comparison of the wet upper Río Madre de Dios watershed with the dry Urubamba-Apurimac river system. Rapid Commun. mass Spectrom. 26, 775-84.

Larsen I. J., Montgomery D. R. and Greenberg H. M. (2014) The contribution of mountains to global denudation. Geology, 1-4.

Lebedeva M. I., Fletcher R. C., Balashov V. N. and Brantley S. L. (2007) A reactive diffusion model describing transformation of bedrock to saprolite. Chem. Geol. 244, 624-645.

Lemarchand E., Chabaux F., Vigier N. and Millot R. (2010) Lithium isotope systematics in a forested granitic catchment (Strengbach, Vosges Mountains, France). Geochim. Cosmochim. Acta 74, 4612-4628.

Li D. D., Jacobson A. D. and Mclnerney D. J. (2014) A reactive-transport model for examining tectonic and climatic controls on chemical weathering and atmospheric $\mathrm{CO} 2$ consumption in granitic regolith. Chem. Geol. 365, 30-42.

Lupker M., France-Lanord C., Galy V., Lavé J., Gaillardet J., Gajurel A. P., Guilmette C., Rahman M., Singh S. K. and Sinha R. (2012) Predominant floodplain over mountain weathering of Himalayan sediments (Ganga basin). Geochim. Cosmochim. Acta 84, 410-432.

Maher K. (2010) The dependence of chemical weathering rates on fluid residence time. Earth Planet. Sci. Lett. 294, 101-110. 
1166

1167

1168

1169

1170

1171

1172

1173

1174

1175

1176

1177

1178

1179

1180

1181

1182

1183

1184

1185

1186

1187

1188

1189

1190

1191

1192

1193

1194

1195

1196

1197

1198

1199

1200

1201

1202

Maher K. (2011) The role of fluid residence time and topographic scales in determining chemical fluxes from landscapes. Earth Planet. Sci. Lett. 312, 48-58.

Maher K. and Chamberlain C. P. (2014) Hydrologic Regulation of Chemical Weathering and the Geologic Carbon Cycle. Science 1502.

McGuire K. J. and McDonnell J. J. (2006) A review and evaluation of catchment transit time modeling. J. Hydrol. 330, 543-563.

McGuire K. J., McDonnell J. J., Weiler M., Kendall C., McGlynn B. L., Welker J. M. and Seibert J. (2005) The role of topography on catchment-scale water residence time. Water Resour. Res. 41, 1-14.

Meade R. H. (1985) Suspended sediment in the Amazon River and its tributaries in Brazil during 1982-84., No. 85-492. US Geological Survey.

Mendívil Echevarría S. and Dávila Manrique D. (1994) Geología de los cuadrángulos de Cuzco y Livitaca.,

Misra S. and Froelich P. N. (2012) Lithium isotope history of Cenozoic seawater: changes in silicate weathering and reverse weathering. Science (80-. ). 335, 818-23.

Montgomery D. R. and Brandon M. T. (2002) Topographic controls on erosion rates in tectonically active mountain ranges. Earth Planet. Sci. Lett. 201, 481-489.

Moon S., Chamberlain C. P. and Hilley G. E. (2014) New estimates of silicate weathering rates and their uncertainties in global rivers. Geochim. Cosmochim. Acta 134, 257-274.

Moquet J.-S., Crave A., Viers J., Seyler P., Armijos E., Bourrel L., Chavarri E., Lagane C., Laraque A., Casimiro W. S. L., Pombosa R., Noriega L., Vera A. and Guyot J.-L. (2011) Chemical weathering and atmospheric/soil $\mathrm{CO} 2$ uptake in the Andean and Foreland Amazon basins. Chem. Geol. 287, 1-26.

Porder S., Vitousek P. M., Chadwick O. a., Chamberlain C. P. and Hilley G. E. (2007) Uplift, Erosion, and Phosphorus Limitation in Terrestrial Ecosystems. Ecosystems 10, 159-171.

Portenga E. W. and Bierman P. R. (2011) Understanding Earth's eroding surface with 10Be. GSA Today 21, 4-10.

Qin J., Huh Y., Edmond J., Du G. and Ran J. (2006) Chemical and physical weathering in the Min Jiang, a headwater tributary of the Yangtze River. Chem. Geol. 227, 53-69.

Quesada C. A., Lloyd J., Anderson L. O., Fyllas N. M., Schwarz M. and Czimczik C. I. (2011) Soils of Amazonia with particular reference to the RAINFOR sites. Biogeosciences 8, 14151440.

Räsänen M., Neller R., Salo J. and Jungner H. (1992) Recent and ancient fluvial deposition systems in the Amazonian foreland basin, Peru. Geol. Mag. 129, 293-306.

Reid E. A., Reid J. S., Meier M. M., Dunlap M. R., Cliff S. S., Broumas A., Perry K. and Maring H. (2003) Characterization of African dust transported to Puerto Rico by individual particle and size segregated bulk analysis. J. Geophys. Res. 108, 1-22. 
1203 Riebe C. S., Kirchner J. W. and FInkel R. C. (2004) Erosional and climatic effects on long-term chemical weathering rates in granitic landscapes spanning diverse climate regimes. Earth Planet. Sci. Lett. 224, 547-562.

1206

1207

1208

1209

1210

1211

1212

1213

1214

1215

1216

1217

1218

1219

1220

1221

1222

1223

1224

1225

1226

1227

1228

1229

1230

1231

1232

1233

1234

1235

1236

1237

1238

1239

Rigsby C. a., Hemric E. M. and Baker P. a. (2009) Late Quaternary Paleohydrology of the Madre de Dios River, southwestern Amazon Basin, Peru. Geomorphology 113, 158-172.

Salve R., Rempe D. M. and Dietrich W. E. (2012) Rain, rock moisture dynamics, and the rapid response of perched groundwater in weathered, fractured argillite underlying a steep hillslope. Water Resour. Res. 48, 1-25.

Stallard R. and Edmond J. (1981) Geochemistry of the Amazon 1. Precipitation chemistry and the marine contribution to the dissolved load at the time of peak discharge. J. Geophys. Res. 86, 9844-9858.

Stallard R. F. (1974) Major Element Geochemistry of the Amazon River. Massachusetts Institute of Technology.

Stallard R. F. and Edmond J. M. (1983) Geochemistry of the Amazon 2. The influence of geology and weathering environment on the dissolved load. J. Geophys. Res. 88, 9671-9688.

Stallard R. and Murphy S. (2014) A Unified Assessment of Hydrologic and Biogeochemical Responses in Research Watersheds in Eastern Puerto Rico Using Runoff-Concentration Relations. Aquat. Geochemistry 20, 115-139.

Stocker T., Qin D., Plattner G.-K., Tignor M., Allen S. K., Boschung J., Nauels A., Xia Y., Bex V. and Midgley P. M. (2014) Climate change 2013: The physical science basis., Cambridge University Press Cambridge, UK, and New York.

Tetzlaff D., Seibert J., McGuire K. J., Laudon H., Burns D. A., Dunn S. M. and Soulsby C. (2009) How does landscape structure influence catchment transit time across different geomorphic provinces? Hydrol. Process. 23, 945-953.

Tipper E. T., Bickle M. J., Galy A., West A. J., Pomiès C. and Chapman H. J. (2006) The short term climatic sensitivity of carbonate and silicate weathering fluxes: Insight from seasonal variations in river chemistry. Geochim. Cosmochim. Acta 70, 2737-2754.

Tobón C., Sevink J. and Verstraten J. M. (2004) Solute fluxes in throughfall and stemflow in four forest ecosystems in northwest Amazonia. Biogeochemistry 70, 1-25.

Torres M. A., West A. J. and Li G. (2014) Sulphide oxidation and carbonate dissolution as a source of CO2 over geological timescales. Nature 507, 346-349.

Vargas Vilchez L. and Hipolito Romero A. (1998) Geología de los cuadrángulos de Río Pinquén, Pilcopata y Chontachaca. Hojas: 25-t, 26-t y 27-t., Instituto Geológica Nacional, Lima, Peru

Walker J., Hays P. and Kasting J. (1981) A negative feedback mechanism for the long-term stabilization of the Earth's surface temperature. J. Geophys. Res. 86, 9776-9782.

West A. J. (2012) Thickness of the chemical weathering zone and implications for erosional and climatic drivers of weathering and for carbon-cycle feedbacks. Geology 40, 811-814. 
1240 West A. J., Bickle M., Collins R. and Brasington J. (2002) Small-Catchment Perspective on $1241 \quad$ Himalayan Weathering Fluxes. Geology 30, 355-358.

1242 West A. J., Galy A. and Bickle M. (2005) Tectonic and Climatic Controls on Silicate Weathering. Earth Planet. Sci. Lett. 235, 211-228.

1244 Whitaker J., Ostle N., Nottingham A. T., Ccahuana A., Salinas N., Bardgett R. D., Meir P. and

1245

1246

1247 McNamara N. P. (2014) Microbial community composition explains soil respiration responses to changing carbon inputs along an Andes-to-Amazon elevation gradient ed. A. Austin. J. Ecol. 102, 1058-1071.

1248 Wolff-Boenisch D., Gabet E. J., Burbank D. W., Langner H. and Putkonen J. (2009) Spatial variations in chemical weathering and $\mathrm{CO} 2$ consumption in Nepalese High Himalayan catchments during the monsoon season. Geochim. Cosmochim. Acta 73, 3148-3170. 
1253

1254

1255

1256

1257

1258

1259

1260

1261

1262

1263

1264

1265

1266

1267

1268

1269

1270

1271

1272

1273

1274

1275

1276

1277

1278

1279

1280

1281

1282

1283

1284

1285

1286

1287

1288

1289

1290

1291

1292

1293

1294

1295

1296

1297

1298

1299

1300

1301

1302

1303
Figure Captions

FIGURE 1. Map of the study site. (A) The points indicate the approximate locations of the time-series sampling localities studied along the Kosñipata-Madre de Dios river system in the Peruvian Andes and lowland Amazon. The areas upstream of each of the four locations define the four nested catchments, with mean elevation and total area for each of the catchments reported. (B) Inset showing the location of the study region within the larger Amazon system.

FIGURE 2. Example of the atmospheric input correction method. The end-member $\mathrm{Mg} / \mathrm{Cl}^{-}$ratio of precipitation for San Pedro was calculated using a linear fit to the measured $\mathrm{Na} / \mathrm{Cl}^{-}$and $\mathrm{Mg} / \mathrm{Cl}^{-}$values in the river samples, and the assumed $\mathrm{Na} / \mathrm{Cl}^{-}$ precipitation end-member ratio of 0.857 . Panel A: A plot of $\mathrm{Na} / \mathrm{Cl}$ versus $\mathrm{Mg} / \mathrm{Cl}$ for samples from the San Pedro catchment with logarithmically scaled axes. Both river water and rainwater samples are plotted along with the calculated best-fit value for the atmospheric input $\mathrm{Mg} / \mathrm{Cl}$ ratio and its $95 \%$ confidence interval. Panel B: A plot of $\mathrm{Na} / \mathrm{Cl}$ versus $\mathrm{Mg} / \mathrm{Cl}$ with linearly scales axes showing the degree to which a linear function describes the riverwater data. The same approach was used to determine other element/ $\mathrm{Cl}^{-}$ratios in precipitation for all of the studied catchments (i.e. in addition to $\mathrm{Mg}$, shown here).

FIGURE 3. Wayqecha catchment (Way) concentration-runoff relationships. Concentration-runoff relationships for $\mathrm{Na}$ (panel A), Si (panel B), Li (panel C), and $\mathrm{Sr}$ (panel D) from the Way catchment. Samples are color coded with respect to their collection season. The best-fit trend line for the power law regression using all of the data (i.e. the "total" fit) is shown as a dashed black line. Samples included in the dominant fit, which is presented as a solid black line, are presented as circles. Samples excluded from the dominant fit are presented as squares. For details on how the samples were grouped, see section 3.2.

FIGURE 4. San Pedro catchment (SP) concentration-runoff relationships. Concentration-runoff relationships for $\mathrm{Na}$ (panel A), Si (panel B), Li (panel C), and Sr (panel D) from the SP catchment. Samples are color coded with respect to their collection season. The best-fit trend line for the power law regression using all of the data (i.e. the "total" fit) is shown as a dashed black line. Samples included in the dominant fit, which is presented as a solid black line, are presented as circles. Samples included in the subordinate fit, which is presented as a solid grey line, are presented as squares. For details on how the samples were grouped, see section 3.2.

\section{FIGURE 5. Manu Learning Center catchment (MLC) concentration-runoff} relationships. Concentration-runoff relationships for $\mathrm{Na}$ (panel A), Si (panel B), Li (panel C), and Sr (panel D) from the MLC catchment. Samples are color coded with respect to their collection season. The best-fit trend line for the power law regression using all of the data (i.e. the "total" fit) is shown as a dashed black line. Samples included in the dominant fit, which is presented as a solid black line, are presented as circles. Samples included in the subordinate fit, which is presented as a solid grey line, are presented as squares. For details on how the samples were grouped, see section 3.2. 
FIGURE 6. CICRA catchment concentration-runoff relationships. Concentration-runoff relationships for $\mathrm{Na}$ (panel A), Si (panel B), Li (panel C), and $\mathrm{Sr}$ (panel D) from the CICRA catchment. Samples are color coded with respect to their collection season. The best-fit trend line for the power law regression using all of the data (i.e. the "total" fit) is shown as a dashed black line. Samples included in the dominant fit, which is presented as a solid black line, are presented as circles. Samples excluded from the dominant fit are presented as squares. For details on how the samples were grouped, see section 3.2.

\section{FIGURE 7. Wayqecha catchment (Way) ratio-runoff relationships.} Ratio-runoff relationships for $\mathrm{Ca} / \mathrm{Na}$ (panel A), $\mathrm{Sr} / \mathrm{Na}$ (panel B), $\mathrm{Na} / \mathrm{Si}$ (panel C), and $\mathrm{Li} / \mathrm{Si}$ (panel D) from the Way catchment. Samples are color coded with respect to their collection season. In panel B, the best-fit trend line for the linear regression using all of the data (i.e. the "total" fit) is shown as a solid black line with the black dashed lines showing the $95 \%$ confidence interval. Samples included in the dominant fit are presented as circles. Samples excluded from the dominant fit are presented as squares. For details on how the samples were grouped, see section 3.2.

FIGURE 8. San Pedro catchment (SP) ratio-runoff relationships.

Ratio-runoff relationships for $\mathrm{Ca} / \mathrm{Na}$ (panel A), $\mathrm{Sr} / \mathrm{Na}$ (panel B), $\mathrm{Na} / \mathrm{Si}$ (panel C), and $\mathrm{Li} / \mathrm{Si}$ (panel D) from the SP catchment. Samples are color coded with respect to their collection season. In panel B, the best-fit trend line for the linear regression using all of the data (i.e. the "total" fit) is shown as a solid black line with the black dashed lines showing the $95 \%$ confidence interval. Samples included in the dominant fit are presented as circles. Samples excluded from the dominant fit are presented as squares. For details on how the samples were grouped, see section 3.2.

FIGURE 9. Manu Learning Center catchment (MLC) ratio-runoff relationships. Ratio-runoff relationships for $\mathrm{Ca} / \mathrm{Na}$ (panel A), $\mathrm{Sr} / \mathrm{Na}$ (panel B), $\mathrm{Na} / \mathrm{Si}$ (panel C), and $\mathrm{Li} / \mathrm{Si}$ (panel D) from the MLC catchment. Samples are color coded with respect to their collection season. In panel B, the best-fit trend line for the linear regression using all of the data (i.e. the "total" fit) is shown as a solid black line with the black dashed lines showing the $95 \%$ confidence interval. Samples included in the dominant fit are presented as circles. Samples excluded from the dominant fit are presented as squares. For details on how the samples were grouped, see section 3.2.

FIGURE 10. CICRA catchment ratio-runoff relationships. Ratio-runoff relationships for $\mathrm{Ca} / \mathrm{Na}$ (panel A), $\mathrm{Sr} / \mathrm{Na}$ (panel B), $\mathrm{Na} / \mathrm{Si}$ (panel C), and $\mathrm{Li} / \mathrm{Si}$ (panel D) from the CICRA catchment. Samples are color coded with respect to their collection season. In panel B, the best-fit trend line for the linear regression using all of the data (i.e. the "total" fit) is shown as a solid black line with the black dashed lines showing the 95\% confidence interval. Samples included in the dominant fit are presented as circles. Samples excluded from the dominant fit are presented as squares. For details on how the samples were grouped, see section 3.2.

FIGURE 11. Correlation between the calculated power law exponents and mean catchment slope angle for all solutes. Linear regressions of the power law exponents 
1355 for the dominant fits of all solutes (except $\mathrm{Cl}^{-}$and $\mathrm{K}$ ) against mean catchment slope angles. Here, linear fits are used to capture to broad trends in the data; other functional forms could also be used, but we lack a priori constraints on what is mechanistically appropriate.

FIGURE 12. Correlation between the calculated power law exponents and mean catchment slope angle for $\mathrm{Na}$ and $\mathrm{Si}$. Calculated power law exponents for $\mathrm{Na}$ (magenta circles) and Si (black diamonds) plotted against mean catchment slope angle. Exponents calculated for the total fit are presented as open symbols. Exponents calculated for the dominant fit are presented as solid symbols. Also shown are linear regressions of the power law exponents for the total (dashed lines) and dominant fits (solid lines) against mean catchment slope angle. Here, linear fits are used to capture to broad trends in the data; other functional forms could also be used, but we lack a priori constraints on what is mechanistically appropriate

FIGURE 13. Variation in the Sodium/Silicon and Lithium/Sodium ratios between the sampling localities. The arrows show the schematic trends expected for secondary Si removal from the dissolved load with and without associated Li uptake. The inset shows a linear regression of the CICRA data with the shaded $95 \% \mathrm{Cl}$ and the degrees-

1375

1376

1377

1378

1379

1380

1381

1382

1383

1384

1385

1386

1387

1388

1389

1390

1391

1392

1393

1394

1395

1396

1397

1398

1399

1400

1401

1402

1403 of-freedom adjusted $r_{2}$ value.

FIGURE 14. Schematic of the hypothesized effects of flow path variability on Andean concentration-runoff relationships. At high runoff rates (i.e. subordinate samples/fit), samples collected at the San Pedro gauging station in the Andes reveal coupled changes in the concentration runoff relationships for multiple elements consistent with a switch to rapid, near-surface flow paths (see section 4.3).

FIGURE 15. Schematic of the coupled variation in fluid transit times and mineral residence times and their effects on concentration-runoff relationships across the mountain-to-floodplain transition. The observed variation in the concentration-runoff relationships for bedrock-derived solutes with mean catchment slope angle suggests that erosional processes influence concentration-runoff relationships by modulating the availability of reactive minerals. The greater sensitivity of the low-slope foreland floodplain site to seasonal changes in the isotopic composition of precipitation suggests that fluid transit times may co-vary with the availability of the reactive minerals in this system and further influence the observed variation in concentration-runoff relationships. Together, the combined variation in fluid transit times and mineral residence times determine the sensitivity of solute concentrations and fluxes to runoff. Contours of different power law exponents spanning from dilution (-1) to "chemostasis" (0) illustrate this variable sensitivity for arbitrary values of solute concentrations and runoff rates. For reference, the ranges in power law exponents measured for the Andean sites (blue) and the foreland floodplain site (green) are shown alongside the schematic of concentrationrunoff and flux-runoff relationships.

\section{Table Captions}

TABLE 1. Catchment descriptions.

TABLE 2. Calculated concentration-runoff power law exponents.

1404 
Table 1. Catchment Descriptions

\begin{tabular}{|c|c|c|c|c|}
\hline Gauge Station & $\begin{array}{c}\text { Wayqecha } \\
\text { (Way) }\end{array}$ & $\begin{array}{c}\text { San Pedro } \\
\text { (SP) }\end{array}$ & $\begin{array}{c}\text { Manu } \\
\text { Learning } \\
\text { Center (MLC) }\end{array}$ & $\begin{array}{c}\text { CICRA - Los } \\
\text { Amigos }\end{array}$ \\
\hline Latitude & S13 09.732 & S13 03.444 & S12 47.334 & S12 34.362 \\
\hline Longitude & W71 35.333 & W71 32.664 & W71 23.429 & W70 06.049 \\
\hline Area $\left(\mathrm{km}^{2}\right)$ & 50 & 161 & 6025 & 27830 \\
\hline $\begin{array}{c}\text { mean elevation } \\
(\mathrm{m})\end{array}$ & 3204 & 2778 & 2012 & 822 \\
\hline $\begin{array}{c}\text { median elevation } \\
(\mathrm{m})\end{array}$ & 3242 & 2795 & 1830 & 445 \\
\hline min elevation (m) & 2250 & 1360 & 452 & 219 \\
\hline $\begin{array}{c}\text { max elevation } \\
(\mathrm{m})\end{array}$ & 3910 & 4000 & 5496 & 5496 \\
\hline $\begin{array}{c}\text { mean slope } \\
\text { angle (degrees) }\end{array}$ & 25 & 27 & 22 & 9 \\
\hline $\begin{array}{l}\text { min slope angle } \\
\text { (degrees) }\end{array}$ & 0.64 & 0.55 & 0 & 0 \\
\hline $\begin{array}{c}\text { max slope angle } \\
\text { (degrees) }\end{array}$ & 76.97 & 76.97 & 54.5 & 49.07 \\
\hline $\begin{array}{c}\text { number of } \\
\text { samples }\end{array}$ & 86 & 60 & 52 & 23 \\
\hline
\end{tabular}


Table 2. Summary of the calculated coefficients for the concentration-runoff relationships

\begin{tabular}{|c|c|c|c|c|c|c|c|c|}
\hline \multicolumn{2}{|c|}{ Total Concentrations - b exponent } & $\mathrm{SO}_{4}{ }^{2-}$ & 2 & Li & 2 & Si & 2 & $\mathrm{Sr}$ \\
\hline Wayqecha & total & -0.35 & 0.05 & -0.41 & 0.05 & -0.12 & 0.03 & -0.29 \\
\hline Wayqecha & dominant & -0.38 & 0.04 & -0.46 & 0.04 & -0.13 & 0.03 & -0.35 \\
\hline San Pedro & total & -0.22 & 0.04 & -0.21 & 0.05 & -0.14 & 0.03 & -0.32 \\
\hline San Pedro & dominant & -0.27 & 0.08 & -0.31 & 0.09 & -0.10 & 0.05 & -0.28 \\
\hline San Pedro & subordinante & -1.08 & 0.37 & -1.60 & 0.50 & -0.86 & 0.17 & -1.09 \\
\hline MLC & total & -0.55 & 0.10 & -0.30 & 0.13 & -0.23 & 0.06 & -0.44 \\
\hline MLC & dominant & -0.58 & 0.09 & -0.36 & 0.08 & -0.25 & 0.04 & -0.47 \\
\hline MLC & subordinante & -1.59 & 0.53 & -1.87 & 0.68 & -0.75 & 0.31 & -1.54 \\
\hline CICRA & total & -0.69 & 0.12 & -0.56 & 0.14 & -0.29 & 0.09 & -0.90 \\
\hline CICRA & dominant & -0.86 & 0.19 & -0.75 & 0.27 & -0.40 & 0.12 & -1.15 \\
\hline \multicolumn{2}{|c|}{ Total Concentrations - b exponent } & $\mathrm{Na}$ & 2 & $\mathrm{Ca}$ & 2 & Mg & 2 & \\
\hline Wayqecha & total & -0.33 & 0.04 & -0.30 & 0.05 & -0.34 & 0.05 & \\
\hline Wayqecha & dominant & -0.37 & 0.03 & -0.34 & 0.04 & -0.38 & 0.05 & \\
\hline San Pedro & total & -0.23 & 0.02 & -0.26 & 0.02 & -0.24 & 0.02 & \\
\hline San Pedro & dominant & -0.23 & 0.05 & -0.20 & 0.04 & -0.20 & 0.04 & \\
\hline San Pedro & subordinante & -0.85 & 0.13 & -0.98 & 0.17 & -0.98 & 0.21 & \\
\hline MLC & total & -0.31 & 0.09 & -0.43 & 0.09 & -0.43 & 0.09 & \\
\hline MLC & dominant & -0.35 & 0.07 & -0.46 & 0.07 & -0.47 & 0.06 & \\
\hline MLC & subordinante & -1.33 & 0.40 & -1.37 & 0.40 & -1.42 & 0.40 & \\
\hline CICRA & total & -0.55 & 0.08 & -0.43 & 0.13 & -0.59 & 0.10 & \\
\hline CICRA & dominant & -0.61 & 0.15 & -0.64 & 0.13 & -0.74 & 0.14 & \\
\hline \multicolumn{2}{|c|}{ Corrected Concentrations - b exponent } & $\mathrm{SO}_{4}{ }^{2-}$ & 2 & Li & 2 & Si & 2 & $\mathrm{Sr}$ \\
\hline Wayqecha & total & -0.36 & 0.05 & -0.42 & 0.05 & -0.13 & 0.04 & -0.30 \\
\hline Wayqecha & dominant & -0.39 & 0.04 & -0.46 & 0.04 & -0.14 & 0.03 & -0.36 \\
\hline San Pedro & total & -0.24 & 0.04 & -0.21 & 0.05 & -0.15 & 0.03 & -0.34 \\
\hline San Pedro & dominant & -0.30 & 0.09 & -0.32 & 0.09 & -0.12 & 0.06 & -0.30 \\
\hline San Pedro & subordinante & -1.20 & 0.36 & -1.65 & 0.52 & -0.95 & 0.19 & -1.23 \\
\hline MLC & total & -0.63 & 0.12 & -0.30 & 0.13 & -0.24 & 0.08 & -0.47 \\
\hline MLC & dominant & -0.66 & 0.10 & -0.36 & 0.08 & -0.25 & 0.07 & -0.49 \\
\hline MLC & subordinante & -1.01 & 1.95 & -1.74 & 1.78 & -1.06 & 1.05 & -1.33 \\
\hline CICRA & total & -0.83 & 0.16 & -0.72 & 0.19 & -0.46 & 0.15 & -1.07 \\
\hline CICRA & dominant & -1.07 & 0.30 & -0.75 & 0.27 & -0.65 & 0.21 & -1.40 \\
\hline \multicolumn{2}{|c|}{ Corrected Concentrations - b exponent } & $\mathrm{Na}$ & 2 & $\mathbf{C a}$ & 2 & Mg & 2 & \\
\hline Wayqecha & total & -0.35 & 0.04 & -0.31 & 0.05 & -0.35 & 0.06 & \\
\hline Wayqecha & dominant & -0.38 & 0.03 & -0.36 & 0.04 & -0.40 & 0.05 & \\
\hline San Pedro & total & -0.25 & 0.02 & -0.28 & 0.02 & -0.26 & 0.03 & \\
\hline San Pedro & dominant & -0.26 & 0.05 & -0.22 & 0.04 & -0.23 & 0.05 & \\
\hline San Pedro & subordinante & -0.95 & 0.14 & -1.10 & 0.16 & -1.11 & 0.20 & \\
\hline MLC & total & -0.34 & 0.09 & -0.49 & 0.10 & -0.48 & 0.10 & \\
\hline MLC & dominant & -0.37 & 0.08 & -0.51 & 0.08 & -0.51 & 0.07 & \\
\hline MLC & subordinante & -1.11 & 1.06 & -1.23 & 1.25 & -1.26 & 1.42 & \\
\hline CICRA & total & -0.75 & 0.15 & -0.50 & 0.16 & -0.76 & 0.15 & \\
\hline CICRA & dominant & -0.89 & 0.26 & -0.77 & 0.17 & -1.02 & 0.22 & \\
\hline
\end{tabular}



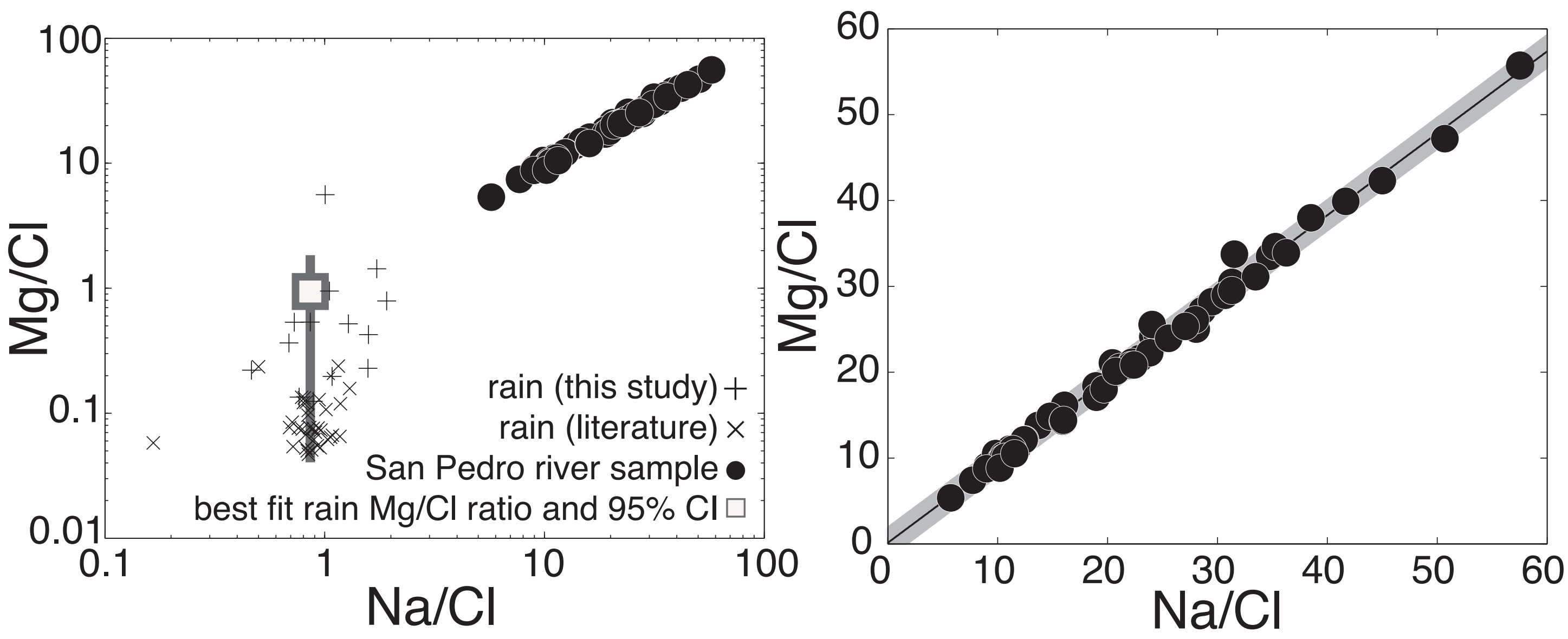


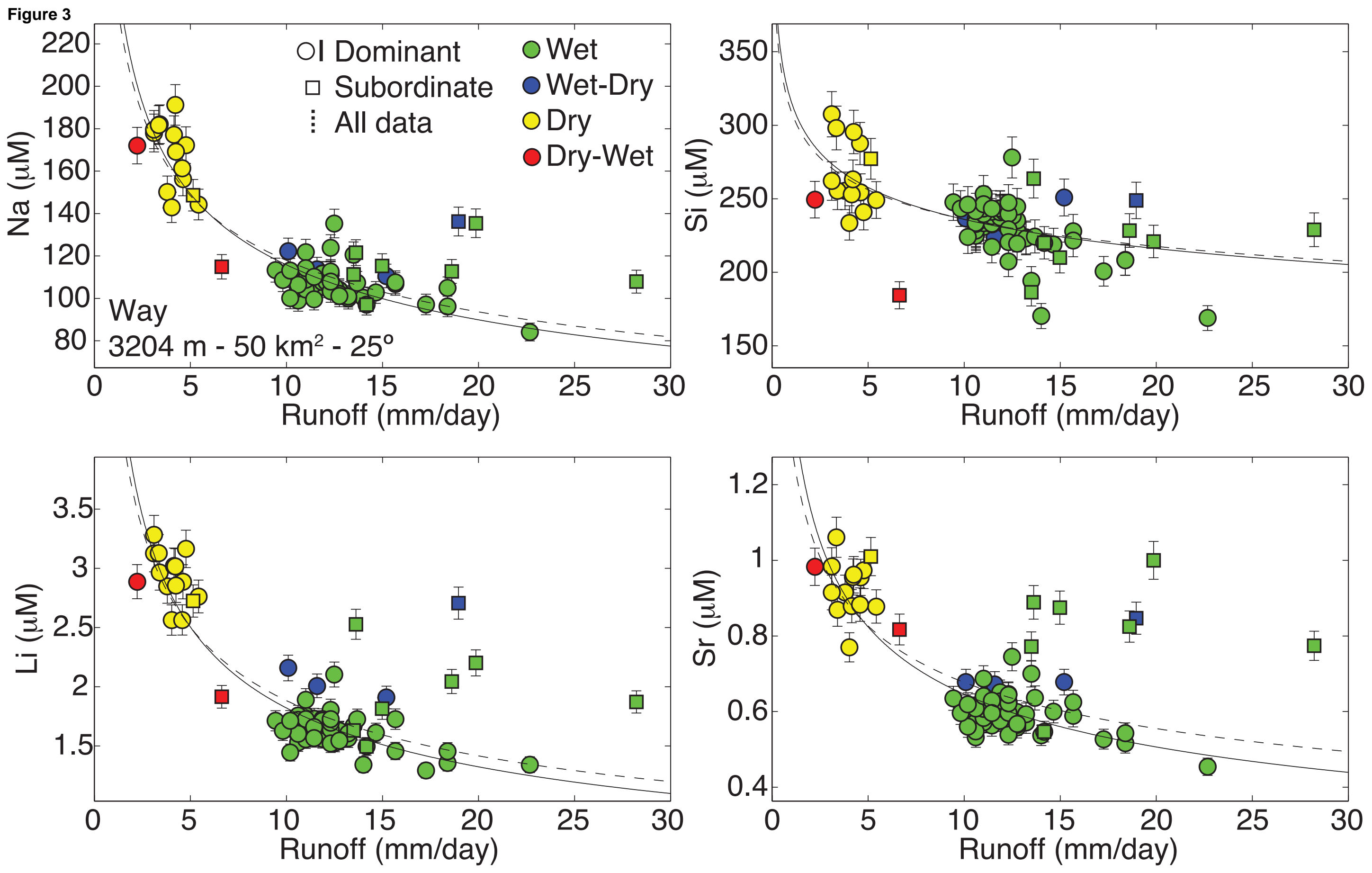




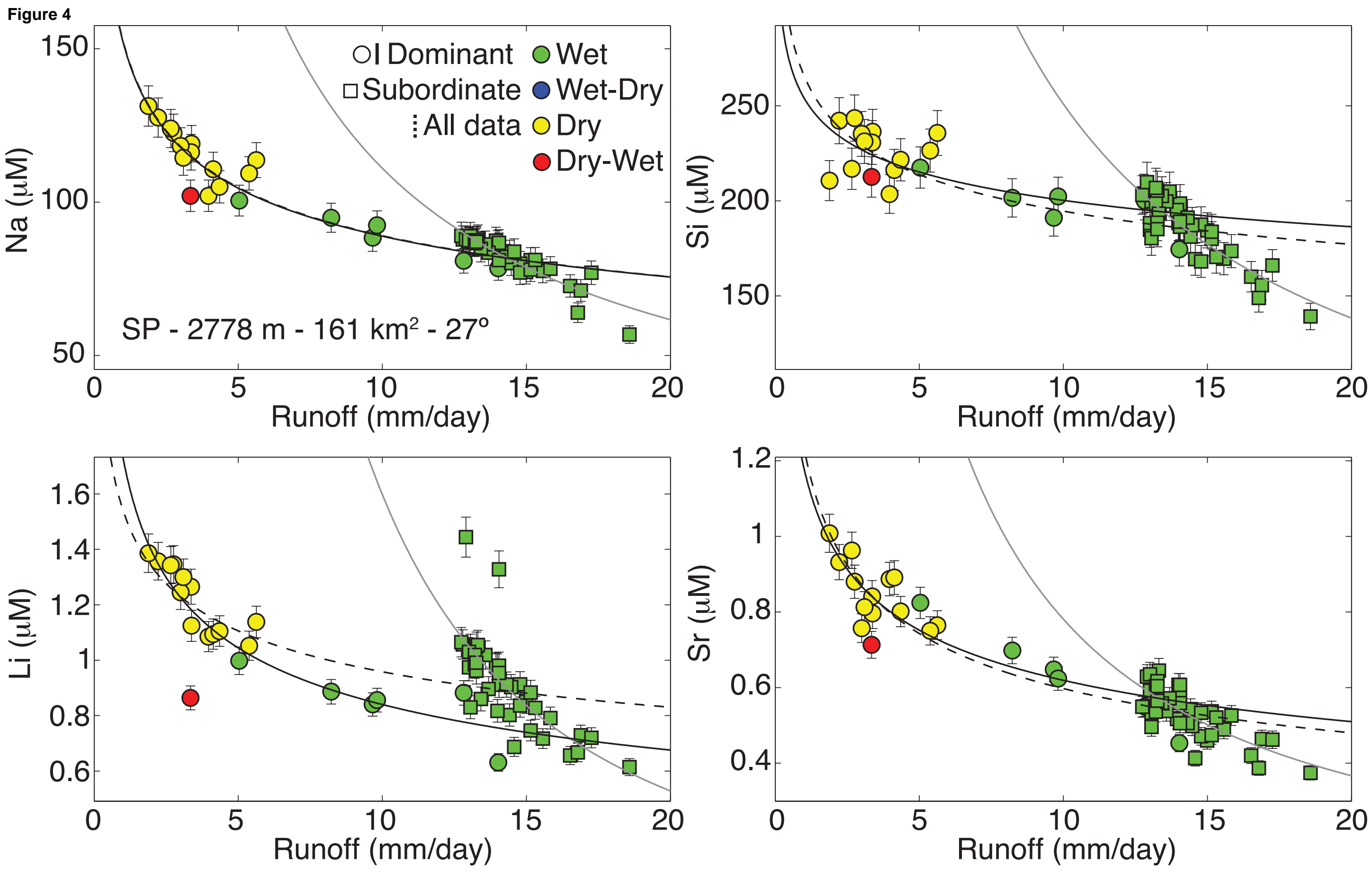




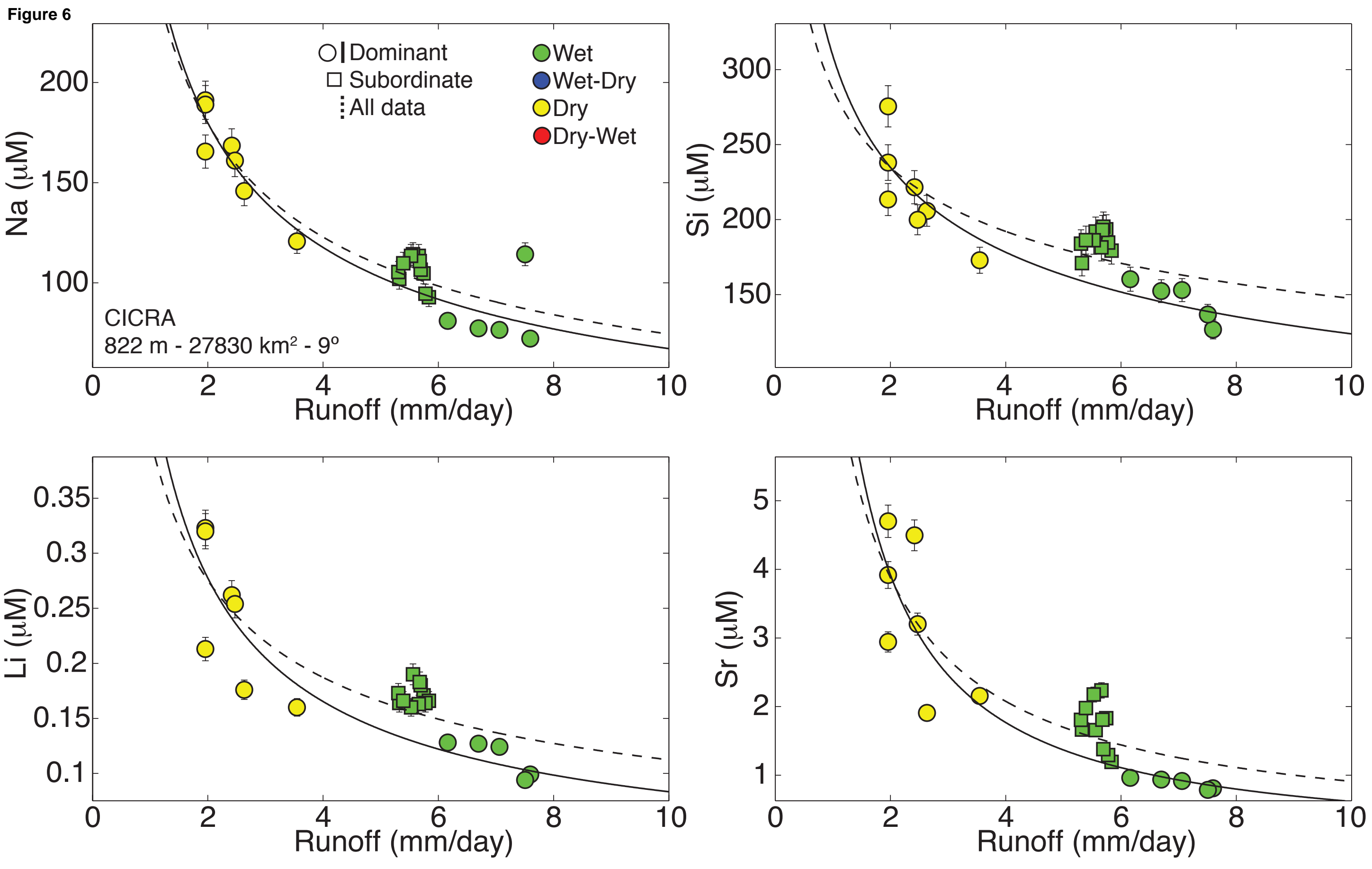



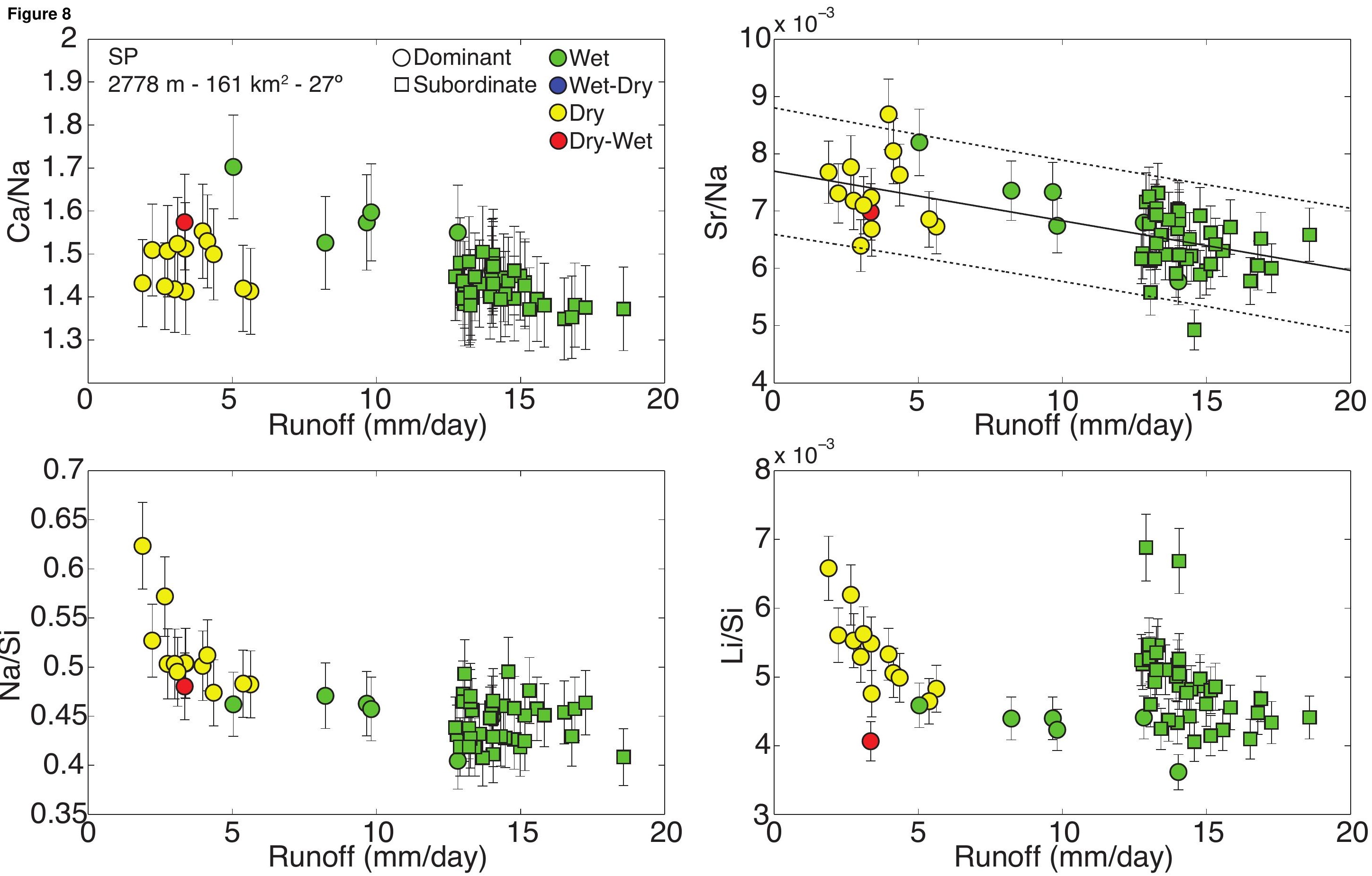


\section{Figure 9}
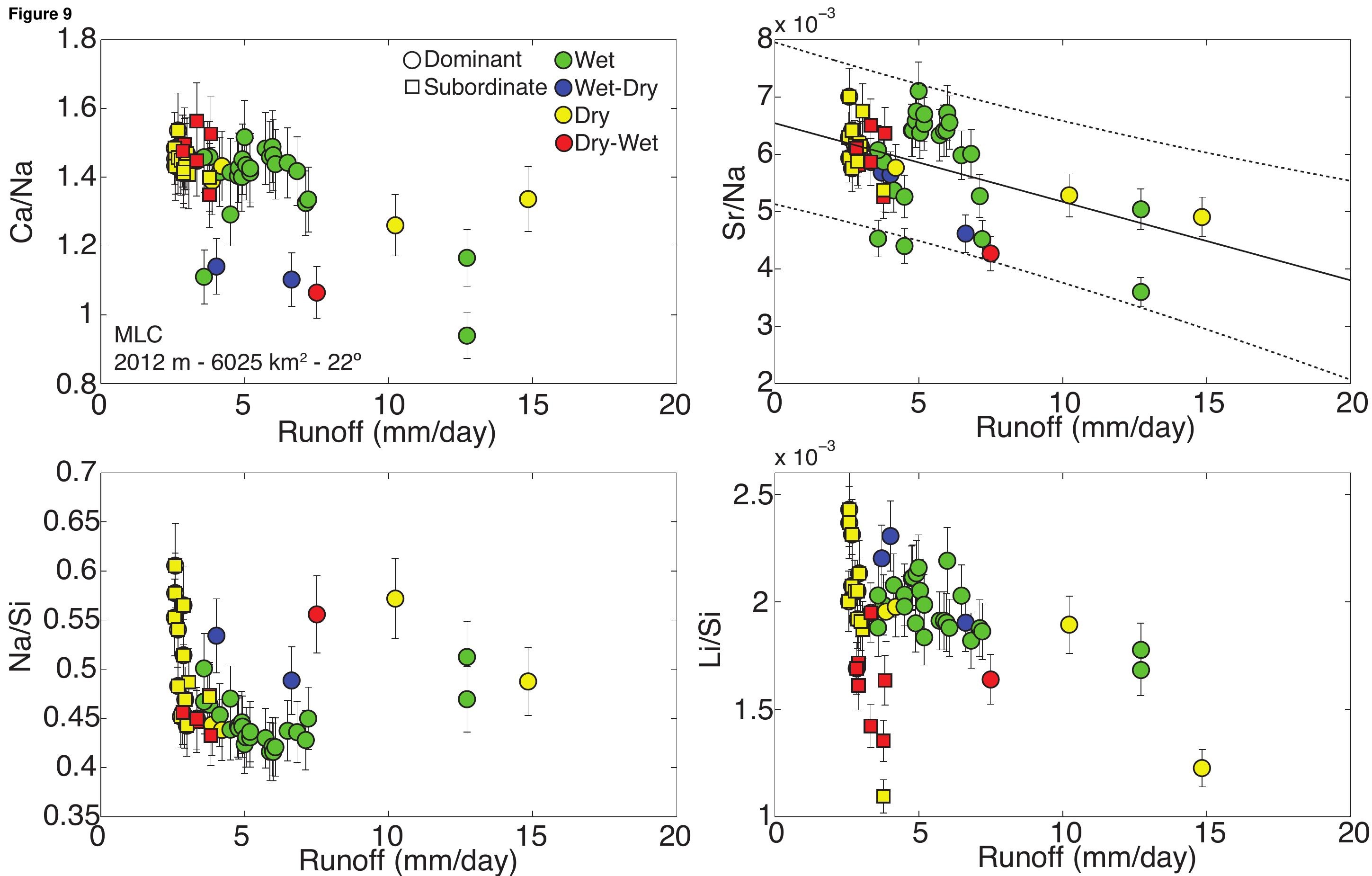

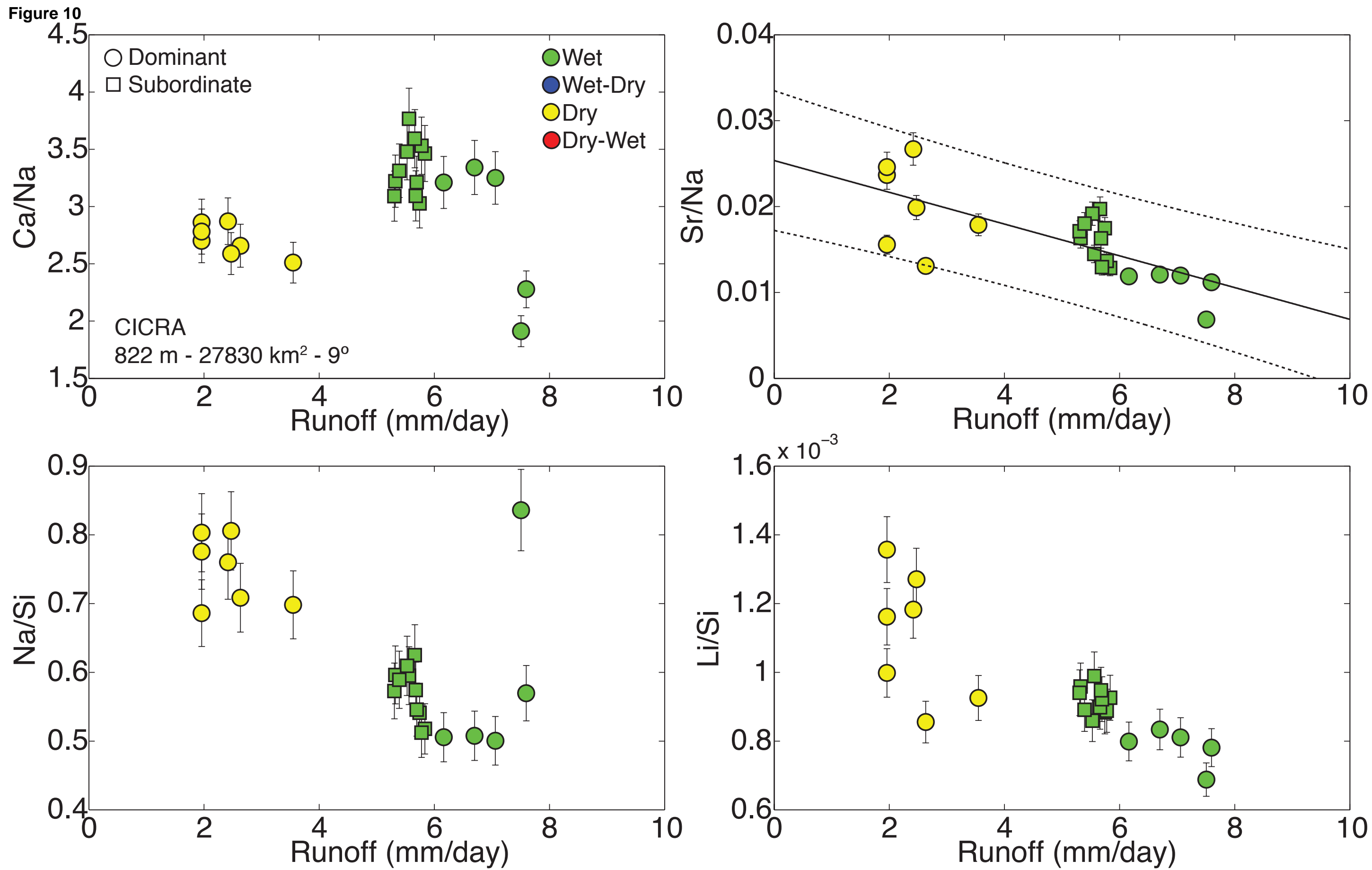

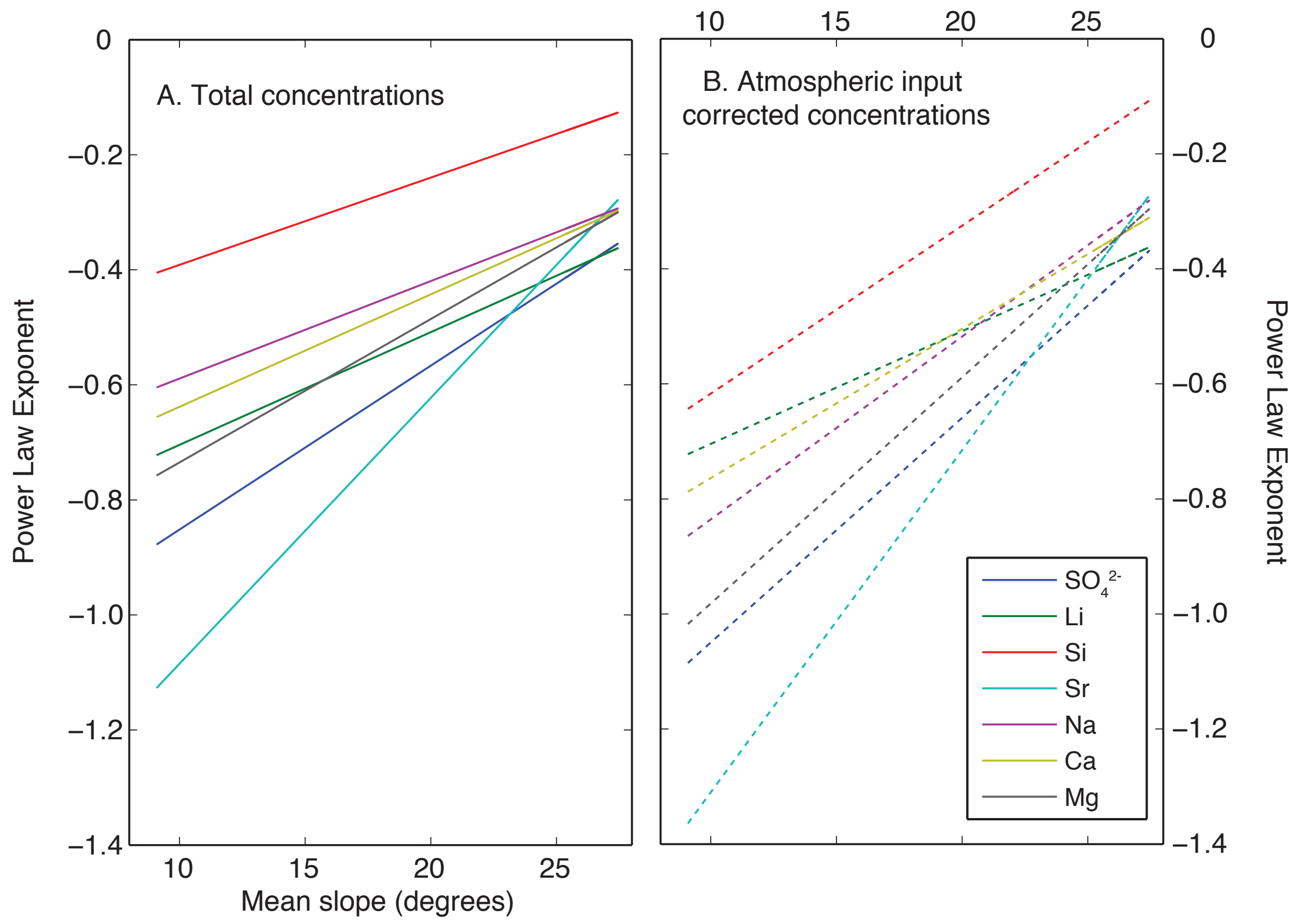


\section{Figure 12 A. Total concentrations}

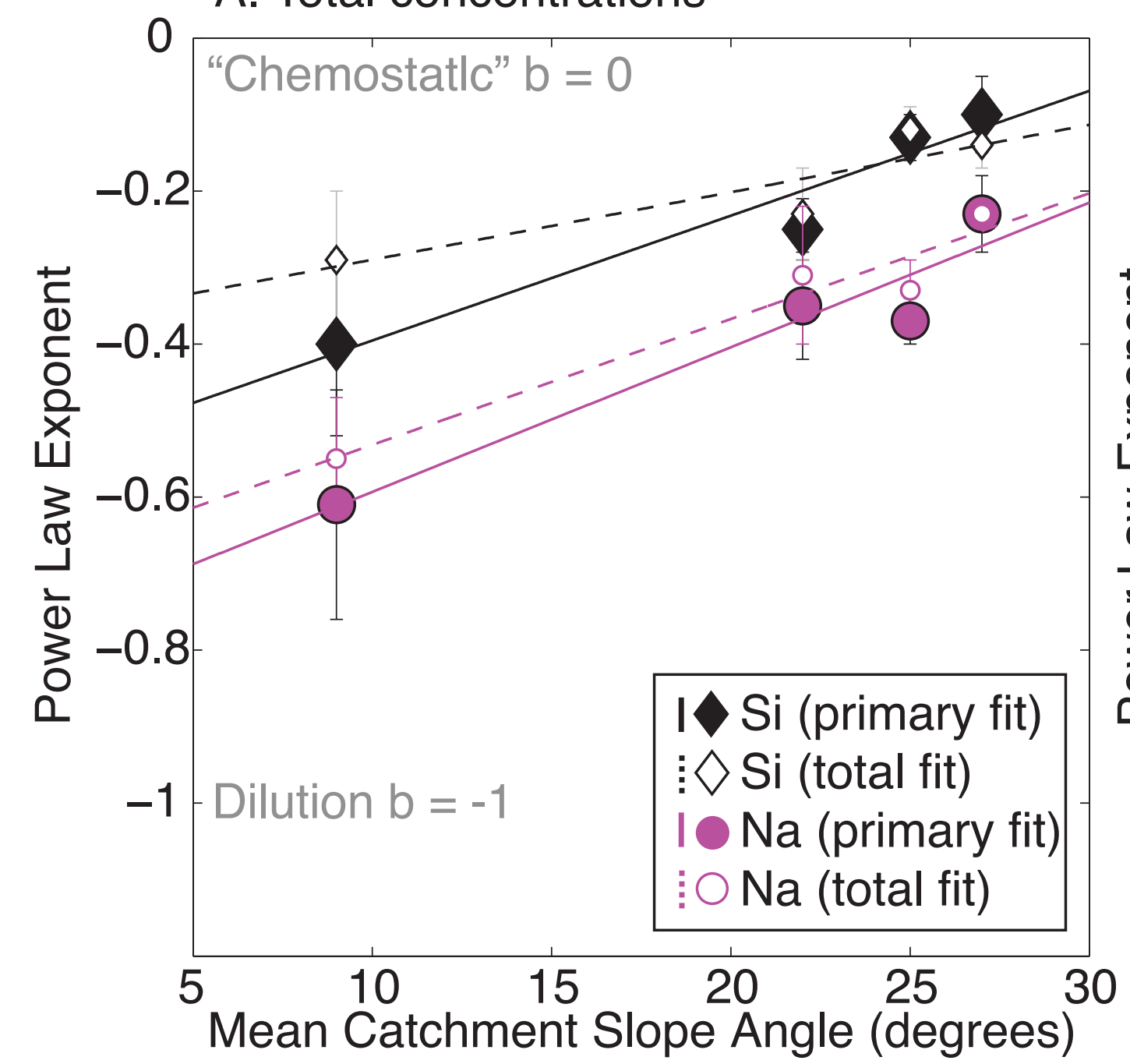

B. Atmospheric input corrected concentrations

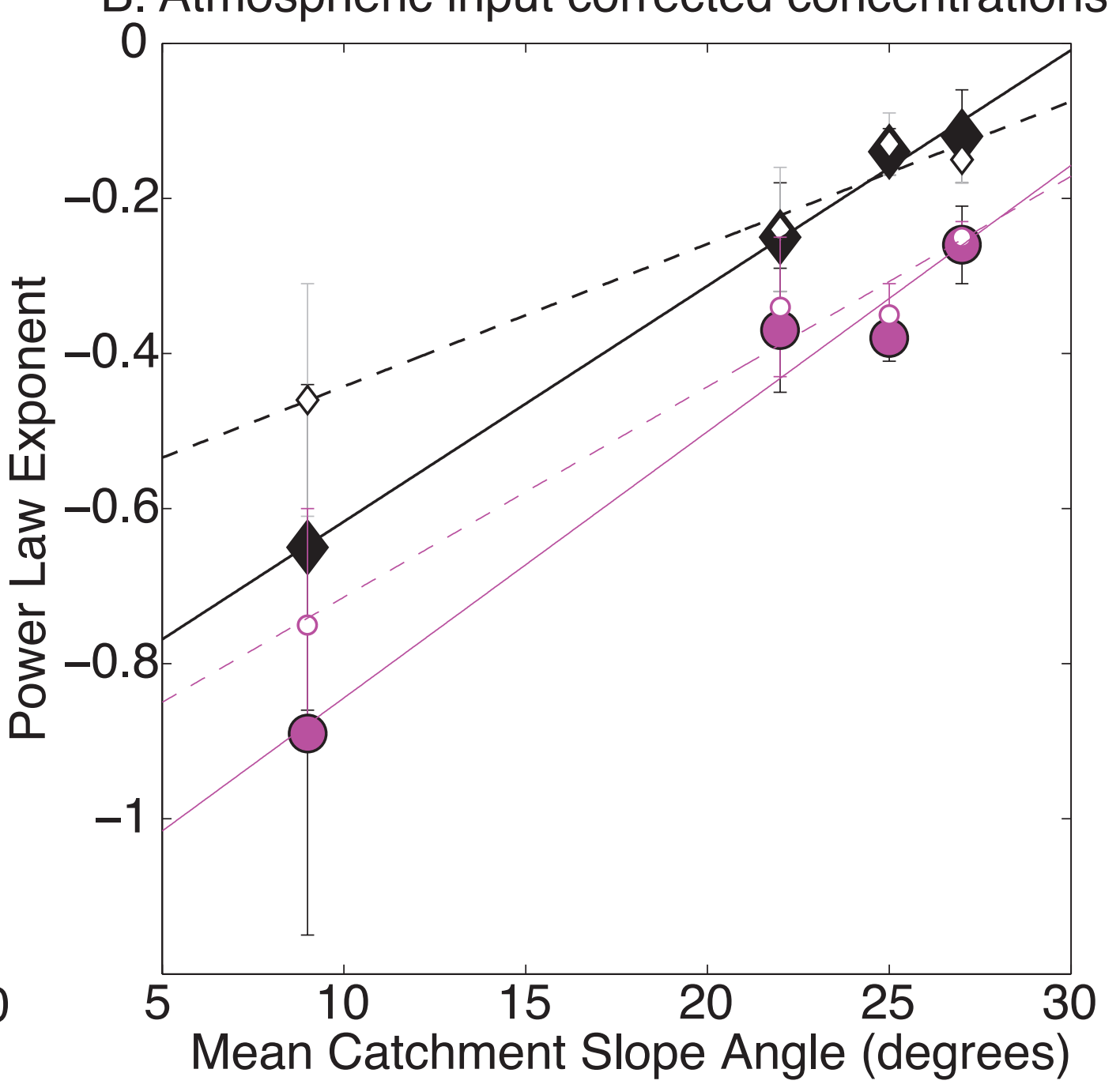


Figure 13

$1000 * \mathrm{Li} / \mathrm{Na}$

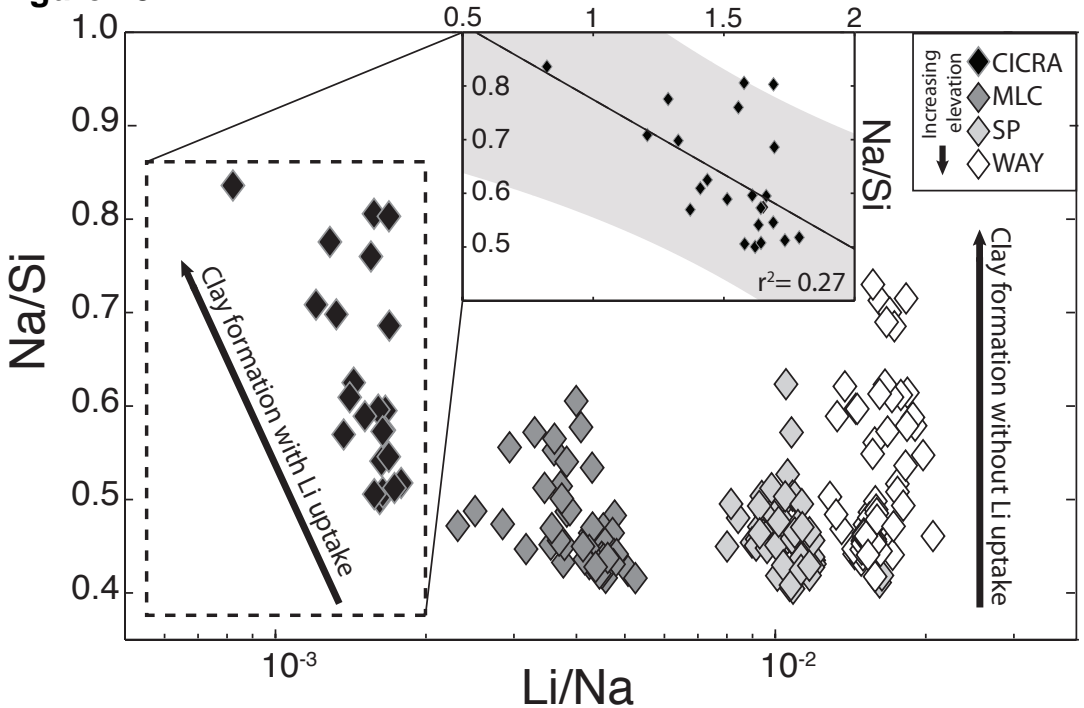


FigyAertelean Catchment Hysteresis

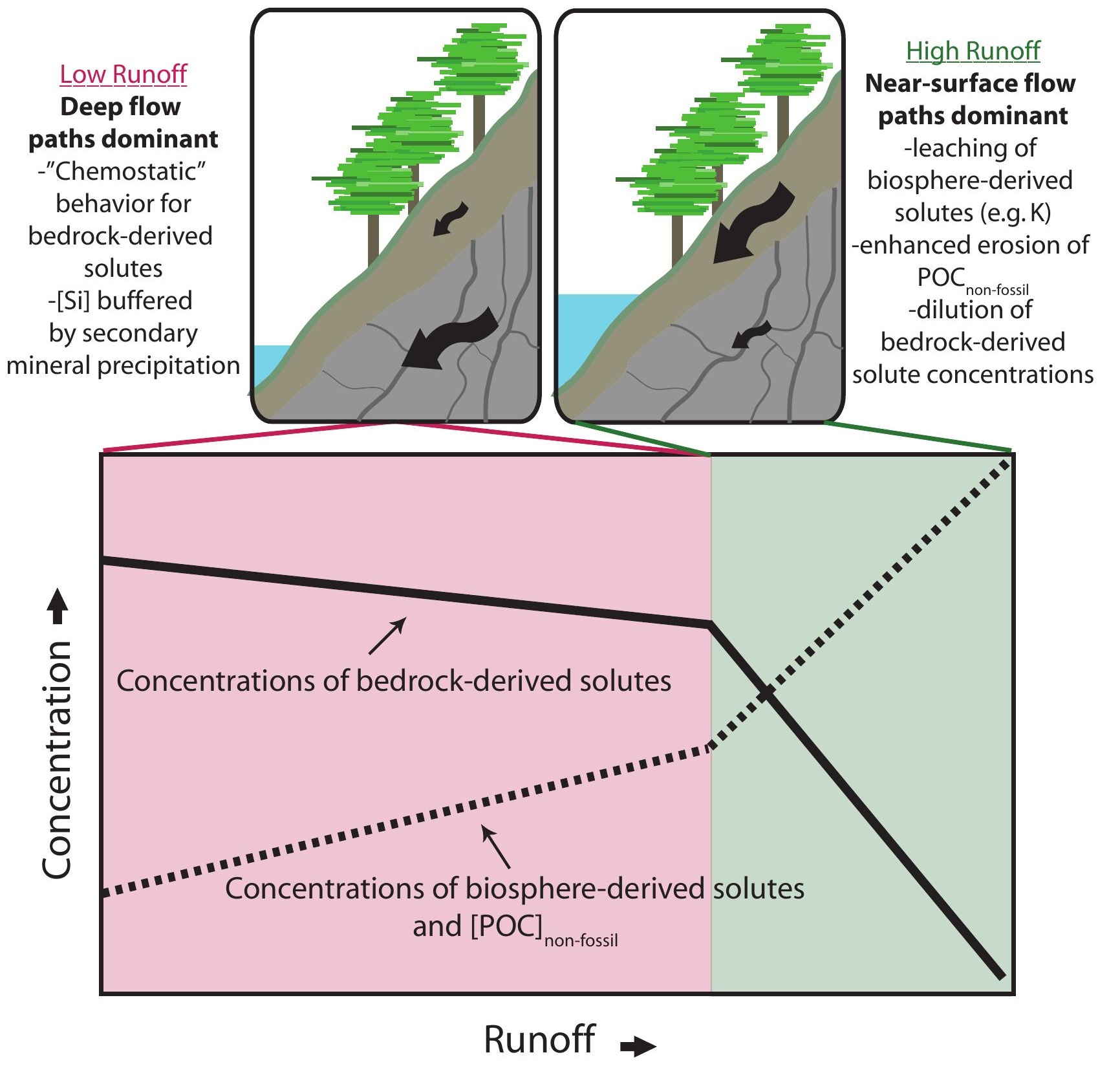


